\title{
CORONAVIRUS
}

\section{Maternal SARS-CoV-2 infection elicits sexually dimorphic placental immune responses}

\author{
Evan A Bordt ${ }^{1 *}$, Lydia L Shook ${ }^{2,3 *}$, Caroline Atyeo ${ }^{4,5 *}$, Krista M Pullen ${ }^{6 *}$, Rose M De Guzman ${ }^{2,3}$, Marie-Charlotte \\ Meinsohn ${ }^{7}$, Maeva Chauvin ${ }^{7}$, Stephanie Fischinger ${ }^{4}$, Laura J. Yockey ${ }^{2,8}$, Kaitlyn James ${ }^{2}$, Rosiane Lima $^{9}$, Lael M \\ Yonker9 , Alessio Fasano ${ }^{9,10}$, Sara Brigida ${ }^{2,3}$, Lisa M Bebell'11, Drucilla J Roberts ${ }^{12}$, David Pépin7 , Jun R Huh ${ }^{13,14}$, \\ Staci D Bilbo ${ }^{1,15}$, Jonathan Z Li ${ }^{16}$, Anjali Kaimal' ${ }^{2}$, Danny Schust ${ }^{17}$, Kathryn J Gray ${ }^{18}$, Douglas Lauffenburger6 \\ Galit Alter ${ }^{4}$, Andrea G Edlow ${ }^{2,3} \uparrow$

\begin{abstract}
${ }^{1}$ Department of Pediatrics, Lurie Center for Autism, Massachusetts General Hospital, Harvard Medical School, Boston, MA, 02129, USA. ${ }^{2}$ Department of Obstetrics and Boston, MA, 02114, USA 4 Ragon Institute of MGH, MIT, and Harvard, Cambridge, MA, 02139, USA 5 PhD Program in Virology, Division of Medical Sciences, Harvard University, Boston, MA, 02115, USA ${ }^{6}$ Department of Biological Engineering, Massachusetts Institute of Technology, Cambridge, MA, 02142, USA 7 Pediatric Surgical Research Laboratories, Department of Surgery, Massachusetts General Hospital, Harvard Medical School, Boston, MA 02114, USA ${ }^{8}$ Department of Medicine, Massachusetts General Hospital, Harvard Medical School, Boston, MA, 02114, USA ${ }^{9}$ Mucosal Immunology and Biology Research Center, Massachusetts General Hospital, Boston, MA, 02129, USA; Department of Pediatrics, Massachusetts General Hospital, Boston, MA, 02114, USA; Harvard Medical School, Boston, MA, USA. ${ }^{10}$ European Biomedical Research Institute of Salerno (EBRIS), Salerno, Italy. ${ }^{11}$ Department of Medicine, Massachusetts General Hospital and Harvard Medical School, Boston, MA 02114, USA ${ }^{12}$ Department of Pathology, Massachusetts General Hospital, Harvard Medical School, Boston, MA, 02114, USA ${ }^{13}$ Department of Immunology, Blavatnik Institute, Harvard Medical School, Boston, MA, 02115, USA ${ }^{14}$ Evergrande Center for Immunologic Diseases, Harvard Medical School and Brigham and Women's Hospital, Boston, MA, 02115, USA ${ }^{15}$ Duke University, Department of Psychology and Neuroscience, Durham, NC, 27708, USA ${ }^{16}$ Department of Medicine, Brigham and Women's Hospital, Boston, MA, 02115, USA ${ }^{17}$ Department of Obstetrics, Gynecology, and Women's Health, University of Missouri, Columbia, MO, 65201, USA ${ }^{18}$ Department of
\end{abstract} \\ Gynecology, Massachusetts General Hospital, Harvard Medical School, Boston, MA, 02114, USA ${ }^{3}$ Vincent Center for Reproductive Biology, Massachusetts General Hospital, \\ Obstetrics and Gynecology, Brigham and Women's Hospital, Harvard Medical School, Boston, MA, 02115, USA
}

*These authors contributed equally to this work

†Corresponding author. Email: aedlow@mgh.harvard.edu

There is a persistent bias toward higher prevalence and increased severity of coronavirus disease 2019 (COVID-19) in males. Underlying mechanisms accounting for this sex difference remain incompletely understood. Interferon responses have been implicated as a modulator of COVID-19 disease in adults, and play a key role in the placental antiviral response. Moreover, the interferon response has been shown to alter Fc receptor expression, and therefore may impact placental antibody transfer. Here we examined the intersection of maternal-fetal antibody transfer, viral-induced placental interferon responses, and fetal sex in pregnant women infected with severe acute respiratory syndrome coronavirus 2 (SARS-CoV-2). Placental Fc receptor abundance, interferon stimulated gene (ISG) expression, and SARS-CoV-2 antibody transfer were interrogated in 68 human pregnancies. Sexually dimorphic expression of placental Fc receptors, ISGs and proteins, and interleukin-10 was observed following maternal SARS-CoV-2 infection, with up-regulation of these features in placental tissue of pregnant individuals with male fetuses. Reduced maternal SARSCoV-2-specific antibody titers and impaired placental antibody transfer were also observed in pregnancies with a male fetus. These results demonstrate fetal sex-specific maternal and placental adaptive and innate immune responses to SARS-CoV-2.

\section{INTRODUCTION}

Mortality and morbidity risk during the perinatal period and infancy is higher in males than females (1-4). The underlying susceptibility of males may relate to evolutionary differences that occur throughout pregnancy and in the perinatal period, but the precise mechanistic differences that lead to this differential female survival benefit is not completely understood. Consistent with perinatal male vulnerability in general, male infants and children fare worse in the setting of severe acute respiratory syndrome coronavirus 2 (SARS-CoV2) infection, with higher rates of severe disease in infants and of SARS-CoV-2-associated multisystem inflammatory syndrome (MIS-C) in male children (5-10). The biological basis for the observed relative vulnerability of the male immune system to SARS-CoV-2 in pediatric populations is likely multifactorial $(11,12)$. Emerging data point to a retrograde impact of infant sex on maternal immunity $(13,14)$, with specific differences in innate immune signaling across fetal sex, which may contribute to a differential dialogue between female and male fetuses and their mothers. This differential dialogue may critically impact immunity across the dyad, pointing to one potential explanation for sex differences in perinatal vulnerability to infectious disease: differential transplacental antibody transfer from the mother may provide female and 
male infants with different degrees of immunity.

Newborn antiviral immunity relies heavily on the placental transfer of maternal immunoglobulin-G (IgG) to the fetal circulation (15-17). Public health strategies to protect newborns from potentially devastating respiratory infections such as pertussis and influenza capitalize on the ability of the placenta to transfer vaccine-induced maternal IgG to the fetal circulation $(18,19)$. Although the neonatal Fc receptor (FcRn) was classically identified as the primary receptor responsible for transferring maternal IgG to fetal circulation (20-22), recent findings have also demonstrated critical roles for the Fc$\curlyvee$ receptors ( $\mathrm{FC} \gamma \mathrm{Rs}) \mathrm{I}-\mathrm{III}$ in facilitating maternal IgG transfer $(15,16,23-25) . \mathrm{FC} \gamma \mathrm{R} 1$ expression is regulated by Type I and II interferons (IFNs), and emerging data have clearly demonstrated perturbed placental transfer in the setting of other coinfections, including human immunodeficiency virus (HIV) (26) and malaria (27). Whether differences in inflammatory responses to SARS-CoV-2 infection could influence placental antibody transfer is unknown. In addition, little is known regarding sex differences in neonatal immune profiles and in maternal-fetal antibody transfer. Recent work has demonstrated reduced transplacental transfer of SARS-CoV2 -specific antibodies relative to influenza and pertussis antibodies $(28,29)$, and associated alterations in expression and localization of specific Fc receptors in the placenta (29), but sex differences in neonatal antibody-mediated immunity to SARS-CoV-2 and in placental receptors involved in antibody transfer have not yet been characterized.

Type I, Type II, and Type III IFNs are induced after innate recognition of viruses (30). Upon binding to their receptors, they induce expression of downstream effectors, interferon stimulated genes (ISGs), which inhibit viral infection by a number of different mechanisms (31). However, viruses have evolved to evade these IFN responses, and IFN responses can also be drivers of inflammatory pathology. Type I IFN signaling correlates strongly with pathogenicity and fatality in both SARS-CoV-1 and Middle East respiratory syndrome coronavirus (MERS-CoV) infections (32-34). Dysregulated Type I IFN signaling is also associated with severe disease and drives pathogenicity in SARS-CoV-2 infection, in both humans and murine models $(33,35-41)$. Notably, sex differences in adult peripheral blood and pulmonary IFN signaling have been observed in both SARS-CoV-1 and SARS-CoV-2 infection (42-44), but there is a dearth of information about sex differences in fetal and pediatric populations. Type I and Type III IFN responses at the maternal-fetal interface play a crucial role in limiting viral infection but may also be drivers of abnormal development (45-47). Less is known about the role of Type II IFN signaling (initiated by IFN- $\gamma$ ) in the placenta, and in SARS-CoV-2 infection (48-53). Sex differences have been noted in the placental immune response to bacterial infection $(54,55)$ and to other prenatal alterations such as maternal stress and maternal high-fat diet $(12,56,57)$. Placental expression of ISGs in maternal SARS-CoV-2 infection, the role of sex differences, and potential impact on placental function have not yet been examined.

Given known sex differences in immune responses to SARS-CoV-2 infection (42), the observed sex differences in disease prevalence and severity in the pediatric population including infants (6-9), and the placenta's critical role as an immune organ mediating antiviral responses and antibody transfer at the maternal-fetal interface (47), we sought to examine sex differences in the placental immune response to SARS-CoV-2 and how this may impact placental expression of receptors associated with antibody transfer. In a cohort of 38 participants infected with SARS-CoV-2 during pregnancy (19 male and 19 female fetuses) and a comparator group of 30 contemporaneously-enrolled pregnant women testing negative for SARS-CoV-2 (15 male and 15 female fetuses), striking differences were noted in placental transfer of antibodies to male and female infants, as well as sexually dimorphic placental $\mathrm{Fc}$ receptor expression and interferon stimulated gene and protein expression in the setting of maternal SARS-CoV-2 infection. These data point to unexpected sex-driven bilateral communication across the maternal-fetal interface, associated with sex differences in SARS-CoV-2specific antibody transfer that may provide insight into sexbased differences in susceptibility to infectious diseases in male infants.

\section{RESULTS \\ Demographic and clinical characteristics of study participants}

Maternal demographic and clinical characteristics of study participants for placental analyses grouped by offspring sex are depicted in Table 1, and those providing matched maternal and umbilical cord blood are depicted in table S1. Of the 68 participants, 34 were pregnant with females and 34 with males. There were no differences between groups with respect to maternal age, parity, obesity, diabetes, hypertension, or gestational age at delivery, among other characteristics examined. Women with SARS-CoV-2 infection during pregnancy were more likely to be Hispanic compared to negative controls, concordant with our prior report of ethnic disparities in COVID-19 vulnerability in our hospital catchment area (58). Of the 38 women with SARS-CoV-2 infection during pregnancy, there were no differences between male and female fetuses with respect to gestational age at diagnosis of SARS-CoV-2 infection, days from positive SARSCoV-2 test to delivery, or severity of coronavirus disease 2019 (COVID-19) illness. Although both male and female fetuses of mothers with SARS-CoV-2 had lower birthweights than their sex-matched control counterparts, clinically this difference was not meaningful as all neonatal birthweights were in the normal range. No neonates born to mothers with SARS-CoV- 
2 infection during pregnancy were infected with SARS-CoV2 .

Sex differences were observed in placental transfer of SARS-CoV-2-specific antibodies and antibody function.

Reduced transplacental antibody transfer has been observed in the context of maternal infections such as HIV (26) and malaria (27), and our group and others have previously described deficits in transplacental antibody transfer of SARS-CoV-2-specific antibodies $(28,29,59,60)$. Given the known vulnerability of male infants to more severe respiratory disease (11), we sought to determine whether the sex of the fetus would impact transplacental transfer of maternal SARS-CoV-2-specific antibodies. We comprehensively profiled SARS-CoV-2 antibodies targeting the spike protein (S), the receptor binding domain (RBD), the spike S1 subunit (S1), the spike $\mathrm{S} 2$ subunit (S2), and the nucleocapsid protein $(\mathrm{N})$ including titer, function, and placental receptor interactions in maternal-cord plasma pairs of SARS-CoV-2 exposed and unexposed (SARS-CoV-2 negative) pregnancies, using a previously-described systems serology approach $(29,61)$. Maternal IgG titers against SARS-CoV-2-specific antigens, an important driver of maternal-fetal immune transfer (62, 63), were significantly lower in mothers carrying a male fetus (Fig. 1A, fig. S1, p < 0.05). Rather than the expected transplacental transfer observed for other pathogens (cord-to-maternal ratio of 1.1 to 1.5 or greater $(24,64,65)$ ), IgG titers against all examined SARS-CoV-2 antigens were significantly reduced in cord relative to maternal plasma across IgG subtypes in pregnancies with a male fetus compared to those with a female fetus (Fig. 1B to F, fig. S2, p $<0.05, \mathrm{p}<0.01$, or $\mathrm{p}<0.001)$. In contrast, significant reduction in cord versus maternal titers was only observed in the case of $\mathrm{N}$ proteinspecific IgG2 in pregnancies with a female fetus (fig. S2, p < $0.05)$. There were significantly reduced cord:maternal transfer ratios for SARS-CoV-2-specific antibodies in male versus female fetuses (Fig. 1G, p < 0.05), and reduced transfer of SARS-CoV-2-specific antibodies capable of binding to FcRn, FC $\curlyvee$ RIIA/B and FC $\curlyvee$ RIIIA/B predominantly in males (Fig. $1 \mathrm{H}$ and fig. S2). Although transfer ratios for SARS-CoV-2-specific antibodies were higher for female fetuses than those of males, they were still lower than the expected 1.1 to 1.5 ratios often observed for other pathogens $(29,64,65)$. SARS-CoV-2specific functional antibodies were also transferred less efficiently, with a marked male-specific decrease in antibody-dependent complement deposition (ADCD)-inducing antibodies and antibodies that induce natural killer (NK) cell chemokine secretion (macrophage inflammatory protein1b/MIP-1b, Fig. 1I and J).

In contrast to SARS-CoV-2-specific antibodies, efficient transfer of pertussis antigen pertactin (PTN) and the influenza hemagglutinin (HA) glycoprotein-specific titers (Fig. 1K, fig. S3) and functions (Fig. II and J) was observed across pregnancies with both female and male fetuses. Timing from maternal vaccination to sample collection for titer determination is depicted in table S2. In addition to influenza and pertussis antibodies, which reflect maternal vaccination during pregnancy, we assessed the transfer of antibodies against endemic, chronic and other childhood vaccinatable pathogens including measles, mumps, rubella, varicella zoster virus (VZV), common coronaviruses NL63 and OC43, cytomegalovirus (CMV) and Epstein-Barr virus (EBV) and found no sex differences in maternal IgG1 titers for these pathogens (fig. S4). We did, however, identify increased transplacental transfer of anti-measles, anti-mumps, antiVZV IgG1 and anti-NL63 IgG1 in females but not males exposed to maternal SARS-CoV-2, relative to sex-matched controls (fig. S4A). Although significantly lower maternal titers of SARS-CoV-2-specific IgG1 were observed in the setting of a male fetus (Fig. 1A, p < 0.05), this effect was specific to antiSARS-CoV-2 antibodies, with no impact of fetal sex on maternal anti-HA, PTN, Tetanus, VZV, CMV, measles, mumps, rubella, NL63, OC43, or EBV titers (fig. S4B and C). Similar results were observed for maternal IgG2, IgG3, and IgM (fig. S5). Overall, these results suggest a reduced maternal SARSCoV-2-specific humoral immune response in pregnancies with male fetuses, consistent with prior studies demonstrating suppressed maternal pro-inflammatory responses in mothers with a male fetus relative to a female fetus $(13,14)$ and the known direct correlation between pro-inflammatory response and increased antibody production in COVID-19 infection $(66,67)$.

Sexually dimorphic placental Fc receptor expression was observed in response to maternal SARS-CoV-2 infection.

The transfer of maternal antibodies across the placenta is mediated by Fc receptors $(15,16)$. FcRn was considered the classical receptor mediating transplacental transfer of IgG (20-22), although other Fc receptors ( $\mathrm{Fc} \curlyvee \mathrm{RI}, \mathrm{Fc} \curlyvee \mathrm{RII}$, and Fc $\gamma$ RIII) are increasingly recognized as being expressed in the placenta and likely to play a role in transfer $(15,16,23-$ 25 ). We observed sexually dimorphic expression of FCGRT, FCGR1, FCGR3A/B genes in the setting of maternal SARS$\mathrm{CoV}-2$ infection (Fig. $2 \mathrm{~A}$ to $\mathrm{C}$, fig. S6A to $\mathrm{C}$, table S3), driven by increased expression in male SARS-CoV-2-exposed placentas. There were no fetal sex or maternal SARS-CoV-2 infection-mediated differences in placental expression of $F C G R 2 A / B$ (fig. S6B and C, table S3). These findings point to sexual dimorphism in Fc receptor expression with up-regulation in male placentas. To distinguish whether increased transcript expression of $\mathrm{Fc}$ receptors was compensatory in the setting of diminished protein expression, or whether protein expression mirrored gene expression, we performed immunoblot analyses of FcRn, FC $\curlyvee \mathrm{RIII}, \mathrm{FC} \gamma \mathrm{RII}$, and $\mathrm{FC}_{\curlyvee} \mathrm{RI}$. 
Protein expression was consistent with gene expression for FcRn, FC $\curlyvee$ RII and FC $\curlyvee$ RIII (Fig. 2D to F, fig. S6D and table S3). There was no impact of maternal SARS-CoV-2 infection nor fetal sex on protein expression of $\mathrm{FC} \gamma \mathrm{R} 1$ (Fig. 2E, table $\mathrm{S} 3$ ). In addition to Fc receptor quantity, it has been demonstrated that co-localization of other Fc $\gamma$ receptors with FcRn typically augments efficiency of placental antibody transfer $(16,29)$. Immunohistochemical analyses of placental villi revealed sexual dimorphism in placental Fc receptor co-localization, with a significant increase in co-localization of FC $\curlyvee$ RIII and FcRn in male placentas only (Fig. 2G and H; table S3, p < 0.01). No fetal sex or maternal SARS-CoV-2 exposure differences in co-localization with FcRn were observed for $\mathrm{FC}_{\curlyvee \mathrm{R} 1}$ (Fig. 2I and J, table S3) or FC $\curlyvee \mathrm{R} 2$ (fig. S6E to G, table S3). The gene and protein expression results suggest that maternal SARS-CoV-2 infection has a sexually dimorphic impact on placental $\mathrm{Fc} \gamma$ receptor expression, driven by an increase in overall expression and increased FC $\gamma \mathrm{R} 3 / \mathrm{FcRn}$ colocalization in male placentas. Increased placental Fc receptor expression was not sufficient to restore normal placental transfer of humoral immunity to male fetuses.

Spike protein-specific Fc-glycan profiles coupled with placental Fc receptor expression patterns drive reduced placental antibody transfer in male pregnancies.

Given that antibody glycosylation has been demonstrated to be a key driver of reduced SARS-CoV-2-specific antibody transfer in maternal-cord dyads (68), we next profiled glycosylation of bulk and spike protein-specific antibodies in SARS-CoV-2-positive pregnancies in the context of a male versus a female fetus. We identified significant differences between bulk and spike protein-specific glycosylation profiles, more pronounced in the context of a male fetus (Fig. 3A and $\mathrm{B}, \mathrm{p}<0.05)$. Spike protein-specific Fc-glycan profiles in SARSCoV-2-positive mothers were marked by enhanced fucosylation (F) and digalactosylation (G2), and reduced bisecting-nacetyl-glucosamine (b-GlcNAc, B) and agalactosylation (G0) on spike protein-specific antibodies in pregnancies with both male and female fetuses (Fig. 3 A and B, fig. S7). Given that fucosylated antibodies are not transferred efficiently through $\mathrm{FC}_{\curlyvee \mathrm{R} 3}$ (69-71), the increased expression of $\mathrm{FC} \gamma \mathrm{R} 3$ and increased co-localization of $\mathrm{FC} \gamma \mathrm{R} 3$ and $\mathrm{FcRn}$ in placentas of SARS-CoV-2-positive male pregnancies may have contributed to impaired placental transfer of SARS-CoV-2-specific antibodies. Due to the attenuated transfer of fucosylated antibodies resulting from up-regulation of $\mathrm{FC} \gamma \mathrm{R} 3$, males preferentially transferred afucosylated antibodies (such as G0 and B), which were relatively scarce among the spike protein-specific antibodies. In contrast, pregnancies with a female fetus had relatively higher maternal titers of SARS-CoV2-specific antibodies, and decreased $\mathrm{FC} \curlyvee \mathrm{R} 3$ placental expression, allowing for more efficient transplacental antibody transfer of the available Fc-glycan profile on spike protein- specific antibodies. Bulk antibodies (including HA, PTN, MMR, VZV, common coronaviruses, CMV, EBV) had a different glycan profile from spike protein-specific antibodies, with bulk antibodies overall enriched for G0 and B (Fig. 3A and B). Sex-specific differences were noted in the glycosylation profile of antibodies transferred from mother to neonate (Fig. 3C). Notably, pregnancies with a male fetus demonstrated significantly increased transfer of agalactosylated (G0), sialyated (S), and bisected GlcNAc (B) spike protein-specific antibodies relative to bulk (Fig. $3 \mathrm{C}, \mathrm{p}<0.05$ ). Although both male and female spike protein-specific transfer of fucosylated (F) antibodies was decreased relative to bulk transfer, only males had impaired transfer of galactosylated (G1) antibodies (Fig. 3C). A possible etiology for the fundamental Fc-glycan differences between spike protein-specific and bulk antibodies within SARS-CoV-2-exposed dyads is the production of SARS-CoV-2-specific antibodies during a de novo infection in pregnancy. Inflammation has been demonstrated to alter the glycosylation profile of antibodies produced during that episode (72), and may be a driver of the differences noted in glycosylation profile of bulk compared to spike protein-specific antibodies.

Sexually dimorphic placental expression of ISGs were observed in response to maternal SARS-COV-2 infection.

Given the key role ISGs are known to play in the placental antiviral response $(46,47,73)$ and placental barrier function (74), and previous reports of sex differences in expression of interferon-stimulated proteins in the plasma of patients with COVID-19 (42), we examined whether maternal SARS-CoV-2 infection was associated with sex-specific alterations in placental Type I, II and III interferon pathways (Fig. S8A). There was a sexually dimorphic expression pattern of the classical ISGs IFI6, CXCL1O, and OAS1, driven by increased expression in male SARS-CoV-2-exposed placentas compared to SARSCoV-2-negative controls (Fig. 4A to C; table S4). We next examined expression of $C C L 2 / M C P-1$, a type I IFN-stimulated cytokine implicated in monocyte chemotaxis (75) and up-regulated in lung samples from patients with COVID-19 $(39,40)$, as well as $M X 1$, an antiviral response gene induced by type I/III IFNs and up-regulated during SARS-CoV-2 infection (76). Maternal SARS-CoV-2 exposure was associated with increased expression of $C C L 2$ and $M X 1$ in the placenta, with these differences primarily driven by increases in male placentas (Fig. 4D and E; table S4). Although maternal SARSCoV-2 infection did not affect expression of placental TNF, IL6, or CCL7 compared to expression in placentas from women negative for SARS-CoV-2 (Fig. S8B to D; table S4), there was a sexually dimorphic effect of maternal SARS-CoV2 infection on the expression of anti-inflammatory factor IL1O (77), driven by significantly increased expression in SARSCoV-2-exposed male placentas (Fig. 4F; table S4, p < 0.01). No 
changes in expression of the reference genes $Y W H A Z$ or TOPI were observed across fetal sex or maternal SARS-CoV-2 status groups (fig. S9, table S4).

To confirm that the sexually dimorphic ISG response was translated at the protein level, we next assessed protein expression within the Type I, II and III interferon-stimulated pathways using a multiplex immunoassay. There was sexually dimorphic expression of placental IFN- $\alpha$ and IFN- $\gamma$, driven by increased IFN expression in male SARS-CoV-2-exposed placentas compared to SARS-CoV-2-negative controls (Fig. $4 \mathrm{G}$ to $\mathrm{H}$ ). Consistent with our gene expression profiling, we confirmed sexually-dimorphic response of interferon-stimulated proteins CXCL10, CCL3, and CCL4 to maternal SARSCoV-2 infection, although protein expression of CCL2 was not different, in contrast to what was observed at the gene level (Fig. 4I and J, fig. S10, table S4). Expression of some interferon-stimulated genes and proteins, in particular CXCL10 and CCL4, was also significantly lower in male compared to female control placentas in the absence of SARS-CoV-2 infection (Fig. 4B, I and $J, p<0.05$ ). Protein analyses confirmed the lack of sex-specific alterations in placental expression of tumor necrosis factor (TNF)- $\alpha$, interleukin (IL)-6, IL-12p70, IL13, IL-17A, IL-8, IL-1a, IL-1b, IL-4, CD62E, or CD62P in the setting of maternal SARS-CoV-2 infection (fig. S10, table S4).

We also observed a male-specific increase in density of $\mathrm{CD} 63^{+}$Hofbauer cells, placental resident fetal macrophages (78), in response to maternal SARS-CoV-2 exposure (Fig. 4K and L; table S4). Although placental Hofbauer cell hyperplasia has been described in maternal SARS-CoV-2 infection $(79,80)$, sex differences have not yet been examined, and may reflect a sex-specific fetal placental immune response to maternal SARS-CoV-2 infection. Together, these results suggest a sex-specific, and in some cases, sexually dimorphic response of placental ISGs to maternal SARS-CoV-2 infection, with upregulation of ISGs in male placentas exposed to maternal SARS-CoV-2 infection.

\section{Modeling the relative impact of placental gene ex- pression, antibodyfeatures, and disease timing and se- verity.}

Although we observed sexually dimorphic expression of individual placental genes and sex-biased transplacental antibody transfer in response to maternal SARS-CoV-2 infection, it was still unclear whether placental gene expression influenced the transfer of humoral immunity in a sex-specific manner. To investigate the relationship between fetal sex, placental gene expression, and antibody transfer, we examined whether S1-specific IgG1 transplacental transfer could be predicted by differential inflammatory, Fc receptor, and interferon-stimulated placental gene expression in male and female orthogonal partial least squares discriminant analysis (O-PLSDA) models. S1-specific IgG1 transfer was modeled because the most robust sex difference was noted in the transfer of this antibody (Fig. 1G). Given that transfer of SARS-CoV-2 specific antibodies in fetuses of both sexes was less than the expected cord:maternal ratio of greater than 1.1 to 1.5 , there was no truly high or efficient transfer. Ratio thresholds for distinguishing higher and lower transfer were therefore determined based on the natural distribution of the data. For female neonates, this ratio was 0.85 , and for males, this ratio was 0.5 (reflective of more impaired transfer in males). To investigate whether multivariate analysis could identify gene signatures specific to relatively high or low transfer, we performed O-PLSDA separately on the female and male neonates (Fig. 5A to D). To avoid overfitting the O-PLSDA model, features were reduced to the 'optimal' set of nonredundant features using Least Absolute Shrinkage and Selection Operator (LASSO) feature selection (81). In both male and female pregnancies, high placental expression of FCGR3B was associated with lower IgG1 S1 transfer efficiency (Fig. 5A to D). Interestingly, higher placental ILIO expression was associated with higher IgG1 S1 transfer in female pregnancies, but lower transfer efficiency in male pregnancies (Fig. 5B and D). In male pregnancies, high expression of $O A S 1$ was associated with higher transfer (Fig. 5D). Overall, these O-PLSDA models support a systemic sexually dimorphic response that triggers distinct inflammatory cascades likely critical for driving different titers of antibody production in mothers.

We also examined the sex-specific impacts of other disease and birth-related factors on placental ISG and Fc receptor expression, and placental antibody transfer. Using linear regression and O-PLSDA models, we did not observe an impact of time from infection, disease severity, or maternal labor status on male or female placental expression of any ISGs, pro-inflammatory cytokines, Fc receptors, or IgG transfer (fig. S11). Additionally, though both male and female neonates born to SARS-CoV-2 positive mothers had reduced birthweight compared to sex-matched controls, birthweights were in the normal range for both groups (Table 1) and birthweight did not impact IgG antibody transfer in linear regression models (fig S11). There were also no associations between antibody transfer and days from infection or gestational age at delivery for either male or female neonates (fig. S11). In summary, disease severity, time from infection, maternal labor status, neonatal birthweight, and gestational age at delivery do not appear to confound our findings of decreased transplacental antibody transfer in the context of a male fetus and sexually dimorphic placental gene expression in the context of maternal SARS-CoV-2 infection.

\section{DISCUSSION}

Our results demonstrate the impact of fetal sex on the maternal and placental immune response to SARS-CoV-2, and the potential consequences for neonatal antibody-mediated immunity. We show that maternal SARS-CoV-2 infection is associated with reduced maternal SARS-CoV-2-specific IgG 
titers in the setting of a male fetus. SARS-CoV-2-specific placental antibody transfer to the male fetus was reduced despite up-regulation of placental Fc receptors in SARS-CoV-2exposed male placentas; males were unable to overcome the reduced maternal titers and the highly fucosylated glycan profile of the spike protein-specific antibodies. Mirroring Fc receptor expression, placental expression of interferon stimulated genes and proteins was also sexually dimorphic, with notable up-regulation noted in male placentas in the setting of maternal SARS-CoV-2 infection. Collectively these findings provide evidence of maternal-placental-fetal immune crosstalk in the setting of maternal viral infection, with fetal sex playing a key role in modifying maternal humoral responses and placental innate and adaptive immune responses.

Epidemiologic data point to a persistent male bias in the development and severity of COVID-19 disease in adults, children, and infants $(6,8,9,82,83)$. Male COVID-19 patients are three times as likely to require admission to intensive care units and have higher odds of death than females (84). This male-biased vulnerability to maternal SARS-CoV-2 infection mirrors the male-biased risk of mortality and morbidity across the perinatal period (1-3). Our findings of sexually dimorphic placental innate immune responses to infection, coupled with sex differences in transfer of maternal humoral immunity, may provide insight into increased vulnerability of male infants to morbidity and mortality.

Although the impact of fetal sex is not consistently evaluated in studies of placental function (85), sex-specific alterations in the placental transcriptome have been described in both normal and pathologic pregnancies (86-89). Sex differences in the placental immune response to prenatal infections and other immune stressors have been described in human and animal models (54,90-93), but have not been examined in SARS-CoV-2 infection. Here we report that maternal SARS-CoV-2 infection induces a sexually dimorphic placental antiviral innate immune response, with up-regulation of ISGs in male, but not female, placentas. Male-specific stimulation of placental ISGs following SARS-CoV-2 exposure is consistent with the heightened male immune responses reported in SARS-CoV-2-infected adult and pediatric cohorts $(5$, $6,8-10,42,94)$. Interestingly, although we did not see evidence of maternal viremia nor placental, cord blood, or neonatal SARS-CoV-2 infection $(28,95)$, and the majority of maternal infections represent mild or moderate disease, there is still evidence of altered placental gene expression and an antiviral response in the placentas of male pregnancies. This indicates that even a mild maternal infection in the absence of placental or fetal infection has the potential to affect placental function and fetal development.

Due to their immature immune system, newborns rely on the passive transplacental transfer of maternal antibodies for initial protection against infectious pathogens $(15,18,96)$.
Although previous reports in adults have noted sex differences in the production of SARS-CoV-2-specific antibodies $(42,97)$, sex-biased maternal production and transplacental transfer of SARS-CoV-2-specific antibodies has not been welldescribed. We previously reported impaired placental transfer of maternal SARS-CoV-2-specific antibodies in the setting of maternal COVID-19 $(28,29)$. Although there are known sex differences in adult antibody production in response to SARS-CoV-2 infection $(42,94)$, little is known about sex differences in maternal titers or transplacental antibody transfer $(98,99)$ in the setting of maternal SARS-CoV-2 infection. Our finding of decreased maternal antibody titers against all measured SARS-CoV-2-specific antigens (S, S1, S2, RBD, N) when the fetus was male versus female was a difference not observed for influenza or pertussis-specific antibodies. Reduced maternal SARS-CoV-2-specific IgG titer in male pregnancies was undoubtedly a driver of the reduced transplacental transfer noted in male fetuses (15). This finding of impaired placental transfer of SARS-CoV-2-specific antibodies, more pronounced in males, is consistent with the male-specific reduction of placental transfer of maternal IgG reported in a non-human primate model of maternal stress (98). Reduced maternal antibody titers in the setting of a male fetus were likely attributable to suppressed maternal pro-inflammatory responses in the setting of a male fetus, which have been described in prior studies and may function to improve tolerance of the fetal allograft $(13,14)$. The direct correlation between pro-inflammatory response and increased antibody production noted in COVID-19 infection $(66,67)$ suggests that blunted maternal inflammatory responses in the setting of a male fetus may limit maternal antibody production in the setting of acute infection. Whether the male-biased impairment in placental SARS-CoV-2specific antibody transfer renders male infants more vulnerable to early-life SARS-CoV-2 infection remains unclear, as the amount of antibody necessary for protection against SARS-CoV-2 infection is unknown and there are few sex-disaggregated reports of neonatal $(100,101)$ or infant infection (8).

Although the up-regulation of Fc receptor expression in male placentas may represent a compensatory placental response driven by reduced maternal antibody titer and transplacental transfer of SARS-CoV-2 antibodies $(22,102,103)$, this response was likely reinforced by the increased IFN signaling in males versus females. IFN-stimulated signaling may impact placental antibody transfer via alteration in Fc receptor expression and function (104-106); for example, Type I IFN signaling is known to up-regulate $\mathrm{Fc} \gamma$ receptor expression on monocytes (107). Hofbauer cells, tissue-resident macrophages of the placenta, express Fc $\gamma$ RI, II and III (23). The male-specific Hofbauer cell hyperplasia in placentas exposed to maternal SARS-CoV-2 infection could therefore also be 
contributing to increased placental $\mathrm{Fc} \curlyvee \mathrm{RI}$ and Fc $\curlyvee \mathrm{RIII}$ expression in males.

Although the low maternal antibody titers in male pregnancies may have driven a compensatory up-regulation of $\mathrm{Fc}$ receptors in the male placenta, the up-regulation of $\mathrm{Fc} \gamma \mathrm{RIII}$ and co-localization of Fc $\gamma$ RIII with FcRn in the male placenta likely impeded placental transfer of SARS-CoV-2-specific antibodies, given their distinct Fc-glycan profile. Our Fc-glycan analysis demonstrated that SARS-CoV-2-specific antibodies were highly fucosylated in both male and female pregnancies, a post-translational modification that lowers antibody affinity for Fc $\gamma$ RIII (69-71). The male-specific placental increase in Fc $\gamma$ RIII expression and co-localization of Fc $\gamma$ RIII with FcRn might therefore present an additional impediment to transferring the already-low maternal titers of SARS-CoV-2specific antibodies to the fetus. Males instead preferentially transferred bisected (afucosylated) and agalactosylated (G0), afucosylated spike protein-specific antibodies, as afucosylated antibodies are more easily transferred by Fc $\gamma$ RIII. Given the inflammatory nature of G0 and B antibodies (72, 108, 109), their preferential transfer might promote a more inflammatory immune response in male fetuses.

Innate immune sensing of SARS-CoV-2 involves the activation of type I and type III interferons and up-regulation of ISGs in target cells (110). Given the relative paucity of SARSCoV-2 placental infection (28) in comparison to other pandemic infections such as Zika virus (ZIKV) (111), the increased ISG production and up-regulated IL1O expression in exposed male placentas may be a protective mechanism to prevent direct placental infection and pathology. Indeed, high IFN concentrations during pregnancy have proven protective against placental herpes simplex virus infection (112) and type III IFNs impair ZIKV transplacental transmission (113). Induction of ISGs is likely not universally protective, however. Whereas type III IFNs primarily serve a barrier defense role, type I and type II IFNs can serve a more classical immune activating or inflammatory role $(31,45)$. Animal models of viral infection in pregnancy implicate type I and type II interferons and ISGs in impaired placental development and fetal growth restriction $(46,50,51,114)$, conditions which can have both short- and long-term impact on fetal and offspring health. We demonstrated increased expression of IFN- $-\gamma$, initiator of Type II interferon signaling, in male SARS-CoV-2exposed placentas. IFN- $\checkmark$ and the Type II IFN response have been implicated in placental spiral artery remodeling, and may mediate fetal growth restriction and fetal demise in malarial and Toxoplasma gondii infection in pregnancy (50, 51, 115, 116). A transcriptomic analysis of SARS-CoV-2 response genes demonstrated that IFN- $\gamma$ was an upstream regulator of host viral response in the setting of SARS-CoV-2 infection (117), with higher IFN- $\gamma$ abundance associated with increased risk for SARS-CoV-2 viral entry (52) and increased mortality in moderate and severe COVID-19 illness (53). Thus, it remains unclear if the male-specific up-regulation of ISGs described here is potentially beneficial (protection from viral infection) versus harmful (increased placental inflammation, increased risk for fetal growth restriction or poor placental function). It was noteworthy that female placentas from SARS-CoV-2-negative control pregnancies generally had higher expression of interferon-stimulated genes and proteins than did male SARS-CoV-2-negative placentas. The potential for a baseline female "antiviral placental advantage" is consistent with the established increased vulnerability of the male fetus to in utero insults, including viral and bacterial infection $(92,118)$, and observed sex differences in baseline innate immunity described in non-placental cells and tissues $(12,119)$. These findings highlight the necessity of future studies assessing baseline differences in male and female placental immune responses. The long-term consequences of SARSCoV-2-associated placental induction of Type I, II, and III IFN responses for fetal development and in utero programming of later life metabolic and neurodevelopmental outcomes remains to be determined.

A limitation of our study is the infection of participants primarily in the third trimester, because these samples were collected during the initial wave of the SARS-CoV-2 pandemic in Boston. Whether maternal SARS-CoV-2 infection in the first and second trimester alters ISG and Fc receptor expression, and how such altered expression might durably impact placental immune function, is a question that remains to be answered in future studies. It remains unclear whether the reduced SARS-CoV-2-specific maternal antibody titers, highly fucosylated glycan profile of spike protein-specific antibodies, and attenuated male-specific transplacental antibody transfer are unique to SARS-CoV-2 biology, or whether these phenomena instead reflect a common response to de novo infection during pregnancy. Future studies should assess the effect of fetal sex on maternal SARS-CoV-2 antibody titers and transplacental transfer in women infected prior to pregnancy, and the effect of fetal sex on maternal antibody responses to other de novo infections during pregnancy. In addition, although we found no association between disease severity and placental gene expression or antibody transfer, such examinations were limited by the relatively small number of women with severe or critical illness. Although our results demonstrate male-specific up-regulation of Type I and II IFNs (IFN- $\alpha$ and IFN- $\gamma$ ), and interferon-stimulated genes and proteins downstream of Type I-III signaling cascades, this study did not assess protein expression of Type III IFN$\lambda$. Finally, although our regression models did not find time from infection to delivery to be a substantial contributor to the antibody transfer ratios, we cannot entirely rule out any contribution of timing of maternal infection to the reduced antibody transfer noted in males. However, our robust 
sexually dimorphic gene and protein expression results, with up-regulation of both placental ISGs and Fc receptors in males, demonstrate placental factors are a stronger driver of antibody transfer than any time-from-infection effect.

In conclusion, our comprehensive evaluation of the impact of fetal sex on placental gene expression and transplacental antibody transfer in maternal SARS-CoV-2 infection provides insight into sexually dimorphic or sex-specific placental innate and adaptive immune responses to maternal SARS-CoV-2 infection. The increased impact of maternal SARS-CoV-2 infection on male placental and neonatal immunity highlights the importance of evaluating fetal sex in future studies of placental pathology and infant outcomes in SARS-CoV-2, as well as the critical importance of disaggregating sex data in follow-up studies of offspring neurodevelopmental and metabolic outcomes. These findings may have broader implications for understanding placental immune response, male vulnerability, and passive transfer of maternal antibody in other viral infections. Studies investigating SARS-CoV-2 vaccine safety and efficacy in pregnant women should also evaluate placental immune response and antibody-transfer effects, in addition to neonatal infection rates, and report these data in a sex-disaggregated fashion (120).

\section{MATERIALS AND METHODS \\ Study design}

The primary objective of this study was to assess maternal-fetal antibody transfer, viral-induced placental interferon responses, and the impact of fetal sex in pregnant humans infected with severe acute respiratory syndrome coronavirus 2 (SARS-CoV-2). No sample size calculation was performed as expected effect sizes were not known. Upon enrollment, collected samples were assigned ordinal deidentified sample identification numbers not specific to disease status (SARSCoV-2 positive versus negative). Pregnant women at two tertiary care centers in Boston, Massachusetts were approached for enrollment in a COVID-19 pregnancy biorepository study starting April 2, 2020 (Massachusetts General Hospital and Brigham and Women's Hospital; Mass General Brigham IRB approval \#2020P000804). All participants provided written informed consent (virtual). Pregnant women were eligible for inclusion if they were: (1) 18 years of age or older, (2) able to provide informed consent or had a healthcare proxy to do so, (3) diagnosed with, or at risk for, SARS-CoV-2 infection. Due to wide community spread in Massachusetts during the study period (121), all pregnant women presenting for hospital care were deemed "at risk" for SARS-CoV-2 infection. Universal COVID-19 screening of all patients admitted to the Labor and Delivery units by nasopharyngeal reverse transcription polymerase chain reaction (RT-PCR) testing was performed (initiated April 16, 2020). Maternal SARS-CoV-2 positivity was defined by a positive clinical nasopharyngeal RT-PCR test result. The number of replicates is detailed in figure legends for individual experiments.

\section{Maternal and cord blood collection and processing}

Sample collection protocols have been described in a previous publication (122). Briefly, blood from pregnant women was collected at delivery by venipuncture into EDTA tubes. Umbilical cord blood was collected immediately after delivery. The umbilical cord was wiped clean and blood was drawn directly from the vein using a syringe and transferred to EDTA vacutainer tubes. Blood was centrifuged at $1000 \mathrm{~g}$ for $10 \mathrm{~min}$ at room temperature. Plasma was aliquoted into cryogenic vials and stored at $-80^{\circ} \mathrm{C}$.

\section{Placental sampling and processing}

Fetal side biopsies ( 0.5 cubic centimeter per biopsy) were collected immediately after delivery. Biopsies were taken from two separate locations at least $4 \mathrm{~cm}$ from the cord insertion avoiding surface vasculature, edges, and areas of gross pathology. Fetal membranes were dissected from the fetal and maternal surfaces and not included in the sample. Biopsies were then dissected in half, serially washed in Dulbecco's phosphate-buffered saline (DPBS), submerged in 5 volumes of RNAlater (Invitrogen), and stored at least 24 hours at $4^{\circ} \mathrm{C}$. Excess RNAlater was removed by blotting on Kimwipes, and biopsies were subdivided into $50 \mathrm{mg}$ segments, placed into cryovials, flash frozen in liquid nitrogen and stored at $-80^{\circ} \mathrm{C}$. For histopathological examination, placentas were fixed in formalin, weighed, examined grossly, and routine sections were taken for histopathologic diagnoses per the Amsterdam Consensus Criteria recommendations. Additional details on placental sectioning and staining are provided in the supplementary materials and methods. Placental homogenates were used to determine concentrations of the immune proteins using the Human Inflammation 20plex ProcartaPlex Panel (Thermo Fisher Scientific) according to manufacturer instructions. Immune proteins included IFN- $\alpha$, IFN- $\gamma$, IL-1 $\alpha$, IL-1 $\beta$, IL-4, IL-6, IL-8, IL-12p70, IL-13, IL17A, TNF- $\alpha$, CXCL10, CCL2, CCL3, CCL4, CD62E, and CD62P and protein was quantified using ProcartaPlex Analysis Software (Thermo Fisher Scientific).

\section{Statistical Analyses}

All multivariate analyses were performed using R (version 4.0.0). Multivariate analyses included reverse transcription quantitative PCR (RT-qPCR) and Luminex antibody measurements. Missing data measurements were imputed using the k-nearest neighbor algorithm. Features were then centered and scaled to unit variance. O-PLSDA was performed to classify databased on relative antibody transfer. Prior to building the O-PLSDA models, LASSO feature regularization and variable selection was performed, resulting in a reduced set of features that were consistently included in at least 80 out of 100 LASSO models. O- PLSDA models were built using the $\mathrm{R}$ 'ropls' Bioconductor package (orthI $=1$; PredI=1). Models 
were validated by evaluating the mean accuracy score after 100 trials of five-fold coefficient of variation (CV). Accuracy scores for analogous models with permutated labels and random features were also reported for comparison.

Statistical tests used and statistical significance are reported in the Figure Legends. Statistical analyses were performed using GraphPad Prism 9 and $\mathrm{R}$ (version 4.0.0). Significant differences in participant characteristics were evaluated using Kruskal-Wallis tests for continuous variables and chi-square or Fisher's exact tests for categorical variables. Gene expression measurements, immunoblot measurements, and immunohistochemistry staining comparing maternal SARS-CoV-2 exposure status and fetal sex were evaluated by two-way analysis of variance (two-way ANOVA) with Bonferroni's post-hoc analysis. Kruskal-Wallis test followed by Dunn's post-hoc test was used to determine significant differences between transfer ratios. Wilcoxon matched-pairs signed rank test was performed to determine significant differences between paired maternal-cord blood samples. All linear regression models were built in $\mathrm{R}$ (version 4.0.0) using the 'stats' package. False discovery rate (FDR) multiple comparisons correction was performed for fig. S6 using a corrected p-value of 0.05 as the cutoff for significance.

\section{SUPPLEMENTARY MATERIALS}

www.science.org/doi/10.1126/scitranslmed.abi7428

Supplementary Materials and Methods

Figs. S1 to S11

Tables S1 to S5

Data file S1

\section{REFERENCES AND NOTES}

1. Z. H. Aghai, S. S. Goudar, A. Patel, S. Saleem, S. M. Dhaded, A. Kavi, P. Lalakia, F. Naqvi, P. L. Hibberd, E. M. McClure, T. L. Nolen, P. Iyer, R. L. Goldenberg, R. J. Derman, Gender variations in neonatal and early infant mortality in India and Pakistan: A secondary analysis from the Global Network Maternal Newborn Health Registry. Reprod. Health 17 (Suppl 3), 178 (2020). doi:10.1186/s12978-020-01028-0 Medline

2. N. Turner, K. Danesh, K. Moran, The evolution of infant mortality inequality in the United States, 1960-2016. Sci. Adv. 6, eaba5908 (2020). doi:10.1126/sciadv.aba5908 Medline

3. R. Pongou, Why is infant mortality higher in boys than in girls? A new hypothesis based on preconception environment and evidence from a large sample of twins. Demography 50, 421-444 (2013). doi:10.1007/s13524-012-0161-5 Medline

4. J. E. Tyson, N. A. Parikh, J. Langer, C. Green, R. D. Higgins; National Institute of Child Health and Human Development Neonatal Research Network, Intensive care for extreme prematurity-Moving beyond gestational age. $N$. Engl. J. Med. 358, 1672-1681 (2008). doi:10.1056/NEJMoa073059 Medline

5. L. R. Feldstein, E. B. Rose, A. G. Randolph, Multisystem Inflammatory Syndrome in Children in the United States. Reply. N. Engl. J. Med. 383, 1794-1795 (2020). doi:10.1056/NEJMoa2021680 Medline

6. S. Godfred-Cato, B. Bryant, J. Leung, M. E. Oster, L. Conklin, J. Abrams, K. Roguski, B. Wallace, E. Prezzato, E. H. Koumans, E. H. Lee, A. Geevarughese, M. K. Lash, K. H. Reilly, W. P. Pulver, D. Thomas, K. A. Feder, K. K. Hsu, N. Plipat, G. Richardson, H. Reid, S. Lim, A. Schmitz, T. Pierce, S. Hrapcak, D. Datta, S. B. Morris, K. Clarke, E. Belay; California MIS-C Response Team, COVID-19-Associated Multisystem Inflammatory Syndrome in Children - United States, March-July 2020. MMWR Morb.
Mortal. Wkly. Rep. 69, 1074-1080 (2020). doi:10.15585/mmwr.mm6932e2 Medline

7. F. Götzinger, B. Santiago-García, A. Noguera-Julián, M. Lanaspa, L. Lancella, F. I. Calò Carducci, N. Gabrovska, S. Velizarova, P. Prunk, V. Osterman, U. Krivec, A. Lo Vecchio, D. Shingadia, A. Soriano-Arandes, S. Melendo, M. Lanari, L. Pierantoni, N. Wagner, A. G. L'Huillier, U. Heininger, N. Ritz, S. Bandi, N. Krajcar, S. Roglić, M. Santos, C. Christiaens, M. Creuven, D. Buonsenso, S. B. Welch, M. Bogyi, F. Brinkmann, M. Tebruegge; ptbnet COVID-19 Study Group, COVID-19 in children and adolescents in Europe: A multinational, multicentre cohort study. Lancet Child Adolesc. Health 4, 653-661 (2020). doi:10.1016/S23524642(20)30177-2 Medline

8. L. Kim, M. Whitaker, A. O'Halloran, A. Kambhampati, S. J. Chai, A. Reingold, I. Armistead, B. Kawasaki, J. Meek, K. Yousey-Hindes, E. J. Anderson, K. P. Openo, A. Weigel, P. Ryan, M. L. Monroe, K. Fox, S. Kim, R. Lynfield, E. Bye, S. Shrum Davis, C. Smelser, G. Barney, N. L. Spina, N. M. Bennett, C. B. Felsen, L. M. Billing, J. Shiltz, M. Sutton, N. West, H. K. Talbot, W. Schaffner, I. Risk, A. Price, L. Brammer, A. M. Fry, A. J. Hall, G. E. Langley, S. Garg; COVID-NET Surveillance Team, Hospitalization Rates and Characteristics of Children Aged $<18$ Years Hospitalized with Laboratory-Confirmed COVID-19 - COVID-NET, 14 States, March 1-July 25, 2020. MMWR Morb. Mortal. Wkly. Rep. 69, 1081-1088 (2020). doi:10.15585/mmwr.mm6932e3 Medline

9. L. M. Yonker, A. M. Neilan, Y. Bartsch, A. B. Patel, J. Regan, P. Arya, E. Gootkind, G. Park, M. Hardcastle, A. St John, L. Appleman, M. L. Chiu, A. Fialkowski, D. De la Flor, R. Lima, E. A. Bordt, L. J. Yockey, P. D’Avino, S. Fischinger, J. E. Shui, P. H. Lerou, J. V. Bonventre, X. G. Yu, E. T. Ryan, I. V. Bassett, D. Irimia, A. G. Edlow, G. Alter, J. Z. Li, A. Fasano, Pediatric Severe Acute Respiratory Syndrome Coronavirus 2 (SARS-CoV-2): Clinical Presentation, Infectivity, and Immune Responses. J. Pediatr. 227, 45-52.e5 (2020). doi:10.1016/j.jpeds.2020.08.037 Medline

10. X. Ma, S. Liu, L. Chen, L. Zhuang, J. Zhang, Y. Xin, The clinical characteristics of pediatric inpatients with SARS-CoV-2 infection: A meta-analysis and systematic review. J. Med. Virol. 93, 234-240 (2021). doi:10.1002/jmv.26208 Medline

11. M. Muenchhoff, P. J. R. Goulder, Sex differences in pediatric infectious diseases. J. Infect. Dis. $\mathbf{2 0 9}$ (Suppl 3), S120-S126 (2014). doi:10.1093/infdis/jiu232 Medline

12. S. L. Klein, K. L. Flanagan, Sex differences in immune responses. Nat. Rev. Immunol. 16, 626-638 (2016). doi:10.1038/nri.2016.90 Medline

13. B. D. Taylor, R. B. Ness, M. A. Klebanoff, G. Tang, J. M. Roberts, D. M. Hougaard, K. Skogstrand, C. L. Haggerty, The impact of female fetal sex on preeclampsia and the maternal immune milieu. Pregnancy Hypertens. 12, 53-57 (2018). doi:10.1016/j.preghy.2018.02.009 Medline

14. A. M. Mitchell, M. Palettas, L. M. Christian, Fetal sex is associated with maternal stimulated cytokine production, but not serum cytokine levels, in human pregnancy. Brain Behav. Immun. 60, 32-37 (2017). doi:10.1016/j.bbi.2016.06.015 Medline

15. M. F. Jennewein, B. Abu-Raya, Y. Jiang, G. Alter, A. Marchant, Transfer of maternal immunity and programming of the newborn immune system. Semin. Immunopathol. 39, 605-613 (2017). doi:10.1007/s00281017-0653-x Medline

16. M. F. Jennewein, I. Goldfarb, S. Dolatshahi, C. Cosgrove, F. J. Noelette, M. Krykbaeva, J. Das, A. Sarkar, M. J. Gorman, S. Fischinger, C. M. Boudreau, J. Brown, J. H. Cooperrider, J. Aneja, T. J. Suscovich, B. S. Graham, G. M. Lauer, T. Goetghebuer, A. Marchant, D. Lauffenburger, A. Y. Kim, L. E. Riley, G. Alter, Fc Glycan-Mediated Regulation of Placental Antibody Transfer. Cell 178, 202-215.e14 (2019). doi:10.1016/j.cell.2019.05.044 Medline

17. M. I. de Moraes-Pinto, F. Verhoeff, L. Chimsuku, P. J. Milligan, L. Wesumperuma, R. L. Broadhead, B. J. Brabin, P. M. Johnson, C. A. Hart, Placental antibody transfer: Influence of maternal HIV infection and placental malaria. Arch. Dis. Child. Fetal Neonatal Ed. 79, F202-F205 (1998). doi:10.1136/fn.79.3.F202 Medline

18. M. Albrecht, P. C. Arck, Vertically Transferred Immunity in Neonates: 
Mothers, Mechanisms and Mediators. Front. Immunol. 11, 555 (2020). doi:10.3389/fimmu.2020.00555 Medline

19. CDC, Vaccinating Pregnant Women (2019) (available at https://www.cdc.gov/vitalsigns/maternal-vaccines/index.html).

20. T. Clements, T. F. Rice, G. Vamvakas, S. Barnett, M. Barnes, B. Donaldson, C. E. Jones, B. Kampmann, B. Holder, Update on Transplacental Transfer of IgG Subclasses: Impact of Maternal and Fetal Factors. Front. Immunol. 11, 1920 (2020). doi:10.3389/fimmu.2020.01920 Medline

21. D. C. Roopenian, S. Akilesh, FcRn: The neonatal Fc receptor comes of age. Nat. Rev. Immunol. 7, 715-725 (2007). doi:10.1038/nri2155 Medline

22. N. A. Lozano, A. Lozano, V. Marini, R. J. Saranz, R. S. Blumberg, K. Baker, M. F. Agresta, M. F. Ponzio, Expression of FcRn receptor in placental tissue and its relationship with IgG levels in term and preterm newborns. Am. J. Reprod. Immunol. 80, e12972 (2018). doi:10.1111/aji.12972 Medline

23. D. R. Martinez, G. G. Fouda, X. Peng, M. E. Ackerman, S. R. Permar, Noncanonical placental Fc receptors: What is their role in modulating transplacental transfer of maternal IgG? PLOS Pathog. 14, e1007161 (2018). doi:10.1371/journal.ppat.1007161 Medline

24. D. R. Martinez, Y. Fong, S. H. Li, F. Yang, M. F. Jennewein, J. A. Weiner, E. A. Harrell, J. F. Mangold, R. Goswami, G. R. Seage 3rd, G. Alter, M. E. Ackerman, X. Peng, G. G. Fouda, S. R. Permar, Fc Characteristics Mediate Selective Placental Transfer of IgG in HIV-Infected Women. Cell 178, 190-201.e11 (2019). doi:10.1016/j.cell.2019.05.046 Medline

25. N. E. Simister, C. M. Story, Human placental Fc receptors and the transmission of antibodies from mother to fetus. J. Reprod. Immunol. 37, 1-23 (1997). doi:10.1016/S0165-0378(97)00068-5 Medline

26. P. Cumberland, C. E. Shulman, P. A. C. Maple, J. N. Bulmer, E. K. Dorman, K. Kawuondo, K. Marsh, F. T. Cutts, Maternal HIV infection and placental malaria reduce transplacental antibody transfer and tetanus antibody levels in newborns in Kenya. J. Infect. Dis. 196, 550-557 (2007). doi:10.1086/519845 Medline

27. A. R. D. McLean, D. Stanisic, R. McGready, K. Chotivanich, C. Clapham, F. Baiwog, M. Pimanpanarak, P. Siba, I. Mueller, C. L. King, F. Nosten, J. G. Beeson, S. Rogerson, J. A. Simpson, F. J. I. Fowkes, P. falciparum infection and maternofetal antibody transfer in malaria-endemic settings of varying transmission. PLOS ONE 12, e0186577 (2017). doi:10.1371/journal.pone.0186577 Medline

28. A. G. Edlow, J. Z. Li, A. Y. Collier, C. Atyeo, K. E. James, A. A. Boatin, K. J. Gray, E. A. Bordt, L. L. Shook, L. M. Yonker, A. Fasano, K. Diouf, N. Croul, S. Devane, L. J. Yockey, R. Lima, J. Shui, J. D. Matute, P. H. Lerou, B. O. Akinwunmi, A. Schmidt, J. Feldman, B. M. Hauser, T. M. Caradonna, D. De la Flor, P. D’Avino, J. Regan, H. Corry, K. Coxen, J. Fajnzylber, D. Pepin, M. S. Seaman, D. H. Barouch, B. D. Walker, X. G. Yu, A. J. Kaimal, D. J. Roberts, G. Alter, Assessment of Maternal and Neonatal SARS-CoV2 Viral Load, Transplacental Antibody Transfer, and Placental Pathology in Pregnancies During the COVID-19 Pandemic. JAMA Netw. Open 3, e2030455 (2020). doi:10.1001/jamanetworkopen.2020.30455 Medline

29. C. Atyeo, K. M. Pullen, E. A. Bordt, S. Fischinger, J. Burke, A. Michell, M. D. Slein, C. Loos, L. L. Shook, A. A. Boatin, L. J. Yockey, D. Pepin, M.-C. Meinsohn, N. M. P. Nguyen, M. Chauvin, D. Roberts, I. T. Goldfarb, J. D. Matute, K. E. James, L. M. Yonker, L. M. Bebell, A. J. Kaimal, K. J. Gray, D. Lauffenburger, A. G. Edlow, G. Alter, Compromised SARS-CoV-2specific placental antibody transfer. Cell 184, 628-642.e10 (2021). doi:10.1016/j.cell.2020.12.027 Medline

30. I. Busnadiego, S. Fernbach, M. O. Pohl, U. Karakus, M. Huber, A. Trkola, S. Stertz, B. G. Hale, Antiviral Activity of Type I, II, and III Interferons Counterbalances ACE2 Inducibility and Restricts SARS-CoV-2. mBio 11, e01928-20 (2020). doi:10.1128/mBio.01928-20 Medline

31. H. M. Lazear, J. W. Schoggins, M. S. Diamond, Shared and Distinct Functions of Type I and Type III Interferons. Immunity 50, 907-923 (2019). doi:10.1016/j.immuni.2019.03.025 Medline

32. M. J. Cameron, L. Ran, L. Xu, A. Danesh, J. F. Bermejo-Martin, C. M. Cameron, M. P. Muller, W. L. Gold, S. E. Richardson, S. M. Poutanen, B. M. Willey, M. E. DeVries, Y. Fang, C. Seneviratne, S. E. Bosinger, D. Persad, P. Wilkinson, L. D. Greller, R. Somogyi, A. Humar, S. Keshavjee,
M. Louie, M. B. Loeb, J. Brunton, A. J. McGeer, D. J. Kelvin; Canadian SARS Research Network, Interferon-mediated immunopathological events are associated with atypical innate and adaptive immune responses in patients with severe acute respiratory syndrome. J. Virol. 81, 8692-8706 (2007). doi:10.1128/JVI.00527-07 Medline

33. R. Channappanavar, A. R. Fehr, R. Vijay, M. Mack, J. Zhao, D. K. Meyerholz, S. Perlman, Dysregulated Type I Interferon and Inflammatory Monocyte-Macrophage Responses Cause Lethal Pneumonia in SARSCoV-Infected Mice. Cell Host Microbe 19, 181-193 (2016). doi:10.1016/j.chom.2016.01.007 Medline

34. J. Zhao, K. Li, C. Wohlford-Lenane, S. S. Agnihothram, C. Fett, J. Zhao, M. J. Gale Jr., R. S. Baric, L. Enjuanes, T. Gallagher, P. B. McCray Jr., S. Perlman, Rapid generation of a mouse model for Middle East respiratory syndrome. Proc. Natl. Acad. Sci. U.S.A. 111, 4970-4975 (2014). doi:10.1073/pnas.1323279111 Medline

35. D. Blanco-Melo, B. E. Nilsson-Payant, W.-C. Liu, S. Uhl, D. Hoagland, R. Møller, T. X. Jordan, K. Oishi, M. Panis, D. Sachs, T. T. Wang, R. E. Schwartz, J. K. Lim, R. A. Albrecht, B. R. tenOever, Imbalanced Host Response to SARS-CoV-2 Drives Development of COVID-19. Cell 181, 1036-1045.e9 (2020). doi:10.1016/j.cell.2020.04.026 Medline

36. B. Israelow, E. Song, T. Mao, P. Lu, A. Meir, F. Liu, M. M. Alfajaro, J. Wei, H. Dong, R. J. Homer, A. Ring, C. B. Wilen, A. Iwasaki, Mouse model of SARS-CoV-2 reveals inflammatory role of type I interferon signaling. $J$. Exp. Med. 217, e20201241 (2020). doi:10.1084/jem.20201241 Medline

37. J. S. Lee, S. Park, H. W. Jeong, J. Y. Ahn, S. J. Choi, H. Lee, B. Choi, S. K. Nam, M. Sa, J.-S. Kwon, S. J. Jeong, H. K. Lee, S. H. Park, S.-H. Park, J. Y. Choi, S.-H. Kim, I. Jung, E.-C. Shin, Immunophenotyping of COVID-19 and influenza highlights the role of type I interferons in development of severe COVID-19. Sci. Immunol. 5, eabd1554 (2020). doi:10.1126/sciimmunol.abd1554 Medline

38. C. Lucas, P. Wong, J. Klein, T. B. R. Castro, J. Silva, M. Sundaram, M. K. Ellingson, T. Mao, J. E. Oh, B. Israelow, T. Takahashi, M. Tokuyama, P. Lu, A. Venkataraman, A. Park, S. Mohanty, H. Wang, A. L. Wyllie, C. B. F. Vogels, R. Earnest, S. Lapidus, I. M. Ott, A. J. Moore, M. C. Muenker, J. B. Fournier, M. Campbell, C. D. Odio, A. Casanovas-Massana, R. Herbst, A. C. Shaw, R. Medzhitov, W. L. Schulz, N. D. Grubaugh, C. Dela Cruz, S. Farhadian, A. I. Ko, S. B. Omer, A. Iwasaki; Yale IMPACT Team, Longitudinal analyses reveal immunological misfiring in severe COVID19. Nature 584, 463-469 (2020). doi:10.1038/s41586-020-2588-y Medline 39. C. Qin, L. Zhou, Z. Hu, S. Zhang, S. Yang, Y. Tao, C. Xie, K. Ma, K. Shang W. Wang, D.-S. Tian, Dysregulation of immune response in patients with COVID-19 in Wuhan, China. Clin. Infect. Dis. 71, 762-768 (2020). doi:10.1093/cid/ciaa248 Medline

40. Y. Xiong, Y. Liu, L. Cao, D. Wang, M. Guo, A. Jiang, D. Guo, W. Hu, J. Yang, Z. Tang, H. Wu, Y. Lin, M. Zhang, Q. Zhang, M. Shi, Y. Liu, Y. Zhou, $\mathrm{K}$. Lan, Y. Chen, Transcriptomic characteristics of bronchoalveolar lavage fluid and peripheral blood mononuclear cells in COVID-19 patients. Emerg. Microbes Infect. 9, 761-770 (2020). doi:10.1080/22221751.2020.1747363 Medline

41. Z. Zhou, L. Ren, L. Zhang, J. Zhong, Y. Xiao, Z. Jia, L. Guo, J. Yang, C. Wang, S. Jiang, D. Yang, G. Zhang, H. Li, F. Chen, Y. Xu, M. Chen, Z. Gao, J. Yang, J. Dong, B. Liu, X. Zhang, W. Wang, K. He, Q. Jin, M. Li, J. Wang, Heightened Innate Immune Responses in the Respiratory Tract of COVID-19 Patients. Cell Host Microbe 27, 883-890.e2 (2020). doi:10.1016/j.chom.2020.04.017 Medline

42. T. Takahashi, M. K. Ellingson, P. Wong, B. Israelow, C. Lucas, J. Klein, J. Silva, T. Mao, J. E. Oh, M. Tokuyama, P. Lu, A. Venkataraman, A. Park, F. Liu, A. Meir, J. Sun, E. Y. Wang, A. Casanovas-Massana, A. L. Wyllie, C. B. F. Vogels, R. Earnest, S. Lapidus, I. M. Ott, A. J. Moore, A. Shaw, J. B. Fournier, C. D. Odio, S. Farhadian, C. Dela Cruz, N. D. Grubaugh, W. L. Schulz, A. M. Ring, A. I. Ko, S. B. Omer, A. Iwasaki; Yale IMPACT Research Team, Sex differences in immune responses that underlie COVID-19 disease outcomes. Nature 588, 315-320 (2020). doi:10.1038/s41586-020-2700-3 Medline

43. R. Channappanavar, C. Fett, M. Mack, P. P. Ten Eyck, D. K. Meyerholz, S. 
Perlman, Sex-Based Differences in Susceptibility to Severe Acute Respiratory Syndrome Coronavirus Infection. J. Immunol. 198, 40464053 (2017). doi:10.4049/jimmunol.1601896 Medline

44. N. Gadi, S. C. Wu, A. P. Spihlman, V. R. Moulton, What's Sex Got to Do With COVID-19? Gender-Based Differences in the Host Immune Response to Coronaviruses. Front. Immunol. 11, 2147 (2020). doi:10.3389/fimmu.2020.02147 Medline

45. A. I. Wells, C. B. Coyne, Type III Interferons in Antiviral Defenses at Barrier Surfaces. Trends Immunol. 39, 848-858 (2018). doi:10.1016/j.it.2018.08.008 Medline

46. L. J. Yockey, K. A. Jurado, N. Arora, A. Millet, T. Rakib, K. M. Milano, A. K. Hastings, E. Fikrig, Y. Kong, T. L. Horvath, S. Weatherbee, H. J. Kliman, C. B. Coyne, A. Iwasaki, Type I interferons instigate fetal demise after Zika virus infection. Sci. Immunol. 3, eaao1680 (2018). doi:10.1126/sciimmunol.aao1680 Medline

47. L. J. Yockey, C. Lucas, A. Iwasaki, Contributions of maternal and fetal antiviral immunity in congenital disease. Science 368, 608-612 (2020). doi:10.1126/science.aaz1960 Medline

48. L. C. Platanias, Mechanisms of type-I- and type-II-interferon-mediated signalling. Nat. Rev. Immunol. 5, 375-386 (2005). doi:10.1038/nri1604 Medline

49. A. J. Sadler, B. R. G. Williams, Interferon-inducible antiviral effectors. Nat. Rev. Immunol. 8, 559-568 (2008). doi:10.1038/nri2314 Medline

50. L. J. Yockey, A. Iwasaki, Interferons and Proinflammatory Cytokines in Pregnancy and Fetal Development. Immunity 49, 397-412 (2018). doi:10.1016/j.immuni.2018.07.017 Medline

51. S. P. Murphy, C. Tayade, A. A. Ashkar, K. Hatta, J. Zhang, B. A. Croy, Interferon gamma in successful pregnancies. Biol. Reprod. 80, 848-859 (2009). doi:10.1095/biolreprod.108.073353 Medline

52. J. Heuberger, J. Trimpert, D. Vladimirova, C. Goosmann, M. Lin, R. Schmuck, H.-J. Mollenkopf, V. Brinkmann, F. Tacke, N. Osterrieder, M. Sigal, Epithelial response to IFN- $\checkmark$ promotes SARS-CoV-2 infection. EMBO Mol. Med. 13, e13191 (2021). doi:10.15252/emmm.202013191 Medline

53. A. C. Gadotti, M. de Castro Deus, J. P. Telles, R. Wind, M. Goes, R. Garcia Charello Ossoski, A. M. de Padua, L. de Noronha, A. Moreno-Amaral, C. P. Baena, F. F. Tuon, IFN- $\gamma$ is an independent risk factor associated with mortality in patients with moderate and severe COVID-19 infection. Virus Res. 289, 198171 (2020). doi:10.1016/j.virusres.2020.198171 Medline

54. A. E. Braun, P. A. Carpentier, B. A. Babineau, A. R. Narayan, M. L. Kielhold, H. M. Moon, A. Shankar, J. Su, V. Saravanapandian, U. Haditsch, T. D. Palmer, "Females Are Not Just 'Protected' Males": SexSpecific Vulnerabilities in Placenta and Brain after Prenatal Immune Disruption. eNeuro 6, ENEURO.0358-19.2019 (2019). doi:10.1523/ENEURO.0358-19.2019 Medline

55. I. Trus, D. Udenze, B. Cox, N. Berube, R. E. Nordquist, F. J. van der Staay, Y. Huang, G. Kobinger, D. Safronetz, V. Gerdts, U. Karniychuk, Subclinical in utero Zika virus infection is associated with interferon alpha sequelae and sex-specific molecular brain pathology in asymptomatic porcine offspring. PLOS Pathog. 15, e1008038 (2019). doi:10.1371/journal.ppat.1008038 Medline

56. V. L. Clifton, Review: Sex and the human placenta: mediating differential strategies of fetal growth and survival. Placenta 31 (Suppl), S33-S39 (2010). doi:10.1016/j.placenta.2009.11.010 Medline

57. S. M. Leon-Garcia, H. A. Roeder, K. K. Nelson, X. Liao, D. P. Pizzo, L. C. Laurent, M. M. Parast, D. Y. LaCoursiere, Maternal obesity and sexspecific differences in placental pathology. Placenta 38, 33-40 (2016). doi:10.1016/j.placenta.2015.12.006 Medline

58. I. T. Goldfarb, M. A. Clapp, M. D. Soffer, L. L. Shook, K. Rushfirth, A. G. Edlow, A. A. Boatin, A. J. Kaimal, W. H. Barth Jr., A. S. Bryant, Prevalence and Severity of Coronavirus Disease 2019 (COVID-19) Illness in Symptomatic Pregnant and Postpartum Women Stratified by Hispanic Ethnicity. Obstet. Gynecol. 136, 300-302 (2020). doi:10.1097/AOG.0000000000004005 Medline

59. N. T. Joseph, C. M. Dude, H. P. Verkerke, L. S. Irby, A. L. Dunlop, R. M.
Patel, K. A. Easley, A. K. Smith, S. R. Stowell, D. J. Jamieson, V. Velu, M. L. Badell, Maternal Antibody Response, Neutralizing Potency, and Placental Antibody Transfer After Severe Acute Respiratory Syndrome Coronavirus 2 (SARS-CoV-2) Infection. Obstet. Gynecol. 138, 189-197 (2021). doi:10.1097/AOG.0000000000004440 Medline

60. D. Song, M. Prahl, S. L. Gaw, S. R. Narasimhan, D. S. Rai, A. Huang, C. V. Flores, C. Y. Lin, U. Jigmeddagva, A. Wu, L. Warrier, J. Levan, C. B. T. Nguyen, P. Callaway, L. Farrington, G. R. Acevedo, V. J. Gonzalez, A. Vaaben, P. Nguyen, E. Atmosfera, C. Marleau, C. Anderson, S. Misra, M. Stemmle, M. Cortes, J. McAuley, N. Metz, R. Patel, M. Nudelman, S. Abraham, J. Byrne, P. Jegatheesan, Passive and active immunity in infants born to mothers with SARS-CoV-2 infection during pregnancy: Prospective cohort study. BMJ Open 11, e053036 (2021). doi:10.1136/bmjopen-2021-053036 Medline

61. C. Atyeo, E. A. DeRiso, C. Davis, E. A. Bordt, R. M. DeGuzman, L. L. Shook, L. M. Yonker, A. Fasano, B. Akinwunmi, D. A. Lauffenburger, M. A. Elovitz, K. J. Gray, A. G. Edlow, G. Alter, COVID-19 mRNA vaccines drive differential Fc-functional profiles in pregnant, lactating, and nonpregnant women. Sci. Transl. Med. eabi8631 (2021). 10.1126/scitranslmed.abi8631 Medline

62. P. Palmeira, C. Quinello, A. L. Silveira-Lessa, C. A. Zago, M. CarneiroSampaio, IgG placental transfer in healthy and pathological pregnancies. Clin. Dev. Immunol. 2012, 985646 (2012). doi:10.1155/2012/985646 Medline

63. J. M. Kubiak, E. A. Murphy, J. Yee, K. Cagino, R. L. Friedlander, S. M. Glynn, K. C. Matthews, M. Jurkiewicz, A. C. Sukhu, Z. Zhao, M. Prabhu, L. Riley, Y. J. Yang, SARS-CoV-2 serology levels in pregnant women and their neonates. Am. J. Obstet. Gynecol. doi:10.1016/j.ajog.2021.01.016

64. F. M. Munoz, N. H. Bond, M. Maccato, P. Pinell, H. A. Hammill, G. K. Swamy, E. B. Walter, L. A. Jackson, J. A. Englund, M. S. Edwards, C. M. Healy, C. R. Petrie, J. Ferreira, J. B. Goll, C. J. Baker, Safety and immunogenicity of tetanus diphtheria and acellular pertussis (Tdap) immunization during pregnancy in mothers and infants: A randomized clinical trial. JAMA 311, 1760-1769 (2014). doi:10.1001/jama.2014.3633 Medline

65. G. Gonçalves, F. T. Cutts, M. Hills, H. Rebelo-Andrade, F. A. Trigo, H. Barros, Transplacental transfer of measles and total IgG. Epidemiol. Infect. 122, 273-279 (1999). doi:10.1017/S0950268899002046 Medline

66. M. C. Woodruff, R. P. Ramonell, D. C. Nguyen, K. S. Cashman, A. S. Saini, N. S. Haddad, A. M. Ley, S. Kyu, J. C. Howell, T. Ozturk, S. Lee, N. Suryadevara, J. B. Case, R. Bugrovsky, W. Chen, J. Estrada, A. MorrisonPorter, A. Derrico, F. A. Anam, M. Sharma, H. M. Wu, S. N. Le, S. A. Jenks, C. M. Tipton, B. Staitieh, J. L. Daiss, E. Ghosn, M. S. Diamond, R. H. Carnahan, J. E. Crowe Jr., W. T. Hu, F. E.-H. Lee, I. Sanz, Extrafollicular B cell responses correlate with neutralizing antibodies and morbidity in COVID-19. Nat. Immunol. 21, 1506-1516 (2020). doi:10.1038/s41590-02000814-z Medline

67. W. F. Garcia-Beltran, E. C. Lam, M. G. Astudillo, D. Yang, T. E. Miller, J. Feldman, B. M. Hauser, T. M. Caradonna, K. L. Clayton, A. D. Nitido, M. R. Murali, G. Alter, R. C. Charles, A. Dighe, J. A. Branda, J. K. Lennerz, D. Lingwood, A. G. Schmidt, A. J. Iafrate, A. B. Balazs, COVID-19neutralizing antibodies predict disease severity and survival. Cell 184, 476-488.e11 (2021). doi:10.1016/j.cell.2020.12.015 Medline

68. A. E. Mahan, M. F. Jennewein, T. Suscovich, K. Dionne, J. Tedesco, A. W. Chung, H. Streeck, M. Pau, H. Schuitemaker, D. Francis, P. Fast, D. Laufer, B. D. Walker, L. Baden, D. H. Barouch, G. Alter, Antigen-Specific Antibody Glycosylation Is Regulated via Vaccination. PLOS Pathog. 12, e1005456 (2016). doi:10.1371/journal.ppat.1005456 Medline

69. S. Chung, V. Quarmby, X. Gao, Y. Ying, L. Lin, C. Reed, C. Fong, W. Lau, Z. J. Qiu, A. Shen, M. Vanderlaan, A. Song, Quantitative evaluation of fucose reducing effects in a humanized antibody on $\mathrm{Fc}_{\curlyvee}$ receptor binding and antibody-dependent cell-mediated cytotoxicity activities. MAbs $\mathbf{4}$, 326-340 (2012). doi:10.4161/mabs.19941 Medline

70. D. J. Falconer, G. P. Subedi, A. M. Marcella, A. W. Barb, Antibody Fucosylation Lowers the Fc $\gamma$ RIIIa/CD16a Affinity by Limiting the 
Conformations Sampled by the N162-Glycan. ACS Chem. Biol. 13, 21792189 (2018). doi:10.1021/acschembio.8b00342 Medline

71. T. Li, D. J. DiLillo, S. Bournazos, J. P. Giddens, J. V. Ravetch, L.-X. Wang, Modulating IgG effector function by Fc glycan engineering. Proc. Natl. Acad. Sci. U.S.A. 114, 3485-3490 (2017). doi:10.1073/pnas.1702173114 Medline

72. G. Alter, T. H. M. Ottenhoff, S. A. Joosten, Antibody glycosylation in inflammation, disease and vaccination. Semin. Immunol. 39, 102-110 (2018). doi:10.1016/j.smim.2018.05.003 Medline

73. R. L. Casazza, H. M. Lazear, J. J. Miner, Protective and Pathogenic Effects of Interferon Signaling During Pregnancy. Viral Immunol. 33, 3-11 (2020). doi:10.1089/vim.2019.0076 Medline

74. A. Bayer, N. J. Lennemann, Y. Ouyang, J. C. Bramley, S. Morosky, E. T. D. A. Marques Jr., S. Cherry, Y. Sadovsky, C. B. Coyne, Type III Interferons Produced by Human Placental Trophoblasts Confer Protection against Zika Virus Infection. Cell Host Microbe 19, 705-712 (2016). doi:10.1016/j.chom.2016.03.008 Medline

75. M. H. Lehmann, L. E. Torres-Domínguez, P. J. R. Price, C. Brandmüller, C. J. Kirschning, G. Sutter, CCL2 expression is mediated by type I IFN receptor and recruits NK and T cells to the lung during MVA infection. J. Leukoc. Biol. 99, 1057-1064 (2016). doi:10.1189/jlb.4MA0815-376RR Medline

76. J. Bizzotto, P. Sanchis, M. Abbate, S. Lage-Vickers, R. Lavignolle, A. Toro, S. Olszevicki, A. Sabater, F. Cascardo, E. Vazquez, J. Cotignola, G. Gueron, SARS-CoV-2 Infection Boosts MX1 Antiviral Effector in COVID-19 Patients. iScience 23, 101585 (2020). doi:10.1016/j.isci.2020.101585 Medline

77. V. J. Costela-Ruiz, R. Illescas-Montes, J. M. Puerta-Puerta, C. Ruiz, L. Melguizo-Rodríguez, SARS-CoV-2 infection: The role of cytokines in COVID-19 disease. Cytokine Growth Factor Rev. 54, 62-75 (2020). doi:10.1016/j.cytogfr.2020.06.001 Medline

78. M. Z. Zulu, F. O. Martinez, S. Gordon, C. M. Gray, The Elusive Role of Placental Macrophages: The Hofbauer Cell. J. Innate Immun. 11, 447-456 (2019). doi:10.1159/000497416 Medline

79. J. L. Hecht, B. Quade, V. Deshpande, M. Mino-Kenudson, D. T. Ting, N. Desai, B. Dygulska, T. Heyman, C. Salafia, D. Shen, S. V. Bates, D. J. Roberts, SARS-CoV-2 can infect the placenta and is not associated with specific placental histopathology: A series of 19 placentas from COVID19-positive mothers. Mod. Pathol. 33, 2092-2103 (2020). doi:10.1038/s41379-020-0639-4 Medline

80. F. Facchetti, M. Bugatti, E. Drera, C. Tripodo, E. Sartori, V. Cancila, M. Papaccio, R. Castellani, S. Casola, M. B. Boniotti, P. Cavadini, A. Lavazza, SARS-CoV2 vertical transmission with adverse effects on the newborn revealed through integrated immunohistochemical, electron microscopy and molecular analyses of Placenta. EBioMedicine 59, 102951 (2020). doi:10.1016/j.ebiom.2020.102951 Medline

81. V. Fonti, E. Belitser, Feature selection using lasso, VU Amsterdam Research Paper in Business Analytics 30, 1-25 (2017).

82. C. M. Petrilli, S. A. Jones, J. Yang, H. Rajagopalan, L. O’Donnell, Y. Chernyak, K. A. Tobin, R. J. Cerfolio, F. Francois, L. I. Horwitz, Factors associated with hospital admission and critical illness among 5279 people with coronavirus disease 2019 in New York City: Prospective cohort study. BMJ 369, m1966 (2020). doi:10.1136/bmj.m1966 Medline

83. B. B. Abate, A. M. Kassie, M. W. Kassaw, T. G. Aragie, S. A. Masresha, Sex difference in coronavirus disease (COVID-19): A systematic review and meta-analysis. BMJ Open 10, e040129 (2020). doi:10.1136/bmjopen-2020040129 Medline

84. H. Peckham, N. M. de Gruijter, C. Raine, A. Radziszewska, C. Ciurtin, L. R. Wedderburn, E. C. Rosser, K. Webb, C. T. Deakin, Male sex identified by global COVID-19 meta-analysis as a risk factor for death and ITU admission. Nat. Commun. 11, 6317 (2020). doi:10.1038/s41467-020-197416 Medline

85. N. Walker, P. Filis, U. Soffientini, M. Bellingham, P. J. O'Shaughnessy, P. A. Fowler, Placental transporter localization and expression in the Human: The importance of species, sex, and gestational age differencest.
Biol. Reprod. 96, 733-742 (2017). doi:10.1093/biolre/iox012 Medline

86. S. Buckberry, T. Bianco-Miotto, C. T. Roberts, Imprinted and X-linked non-coding RNAs as potential regulators of human placental function. Epigenetics 9, 81-89 (2014). doi:10.4161/epi.26197 Medline

87. S. Buckberry, T. Bianco-Miotto, S. J. Bent, G. A. Dekker, C. T. Roberts, Integrative transcriptome meta-analysis reveals widespread sex-biased gene expression at the human fetal-maternal interface. Mol. Hum. Reprod. 20, 810-819 (2014). doi:10.1093/molehr/gau035 Medline

88. T. J. Stuart, K. O’Neill, D. Condon, I. Sasson, P. Sen, Y. Xia, R. A. Simmons, Diet-induced obesity alters the maternal metabolome and early placenta transcriptome and decreases placenta vascularity in the mouse. Biol. Reprod. 98, 795-809 (2018). doi:10.1093/biolre/ioy010 Medline

89. T. Sun, T. L. Gonzalez, N. Deng, R. DiPentino, E. L. Clark, B. Lee, J. Tang, Y. Wang, B. R. Stripp, C. Yao, H.-R. Tseng, S. A. Karumanchi, A. F. Koeppel, S. D. Turner, C. R. Farber, S. S. Rich, E. T. Wang, J. Williams III, M. D. Pisarska, Sexually Dimorphic Crosstalk at the Maternal-Fetal Interface. J. Clin. Endocrinol. Metab. 105, e4831-e4847 (2020). doi:10.1210/clinem/dgaa503 Medline

90. M.-J. Allard, A. Giraud, M. Segura, G. Sebire, Sex-specific maternofetal innate immune responses triggered by group B Streptococci. Sci. Rep. 9, 8587 (2019). doi:10.1038/s41598-019-45029-x Medline

91. S. L. Bronson, T. L. Bale, Prenatal stress-induced increases in placental inflammation and offspring hyperactivity are male-specific and ameliorated by maternal antiinflammatory treatment. Endocrinology 155, 2635-2646 (2014). doi:10.1210/en.2014-1040 Medline

92. R. L. Goldenberg, W. W. Andrews, O. M. Faye-Petersen, A. R. Goepfert, S. P. Cliver, J. C. Hauth, The Alabama Preterm Birth Study: Intrauterine infection and placental histologic findings in preterm births of males and females less than 32 weeks. Am. J. Obstet. Gynecol. 195, 1533-1537 (2006). doi:10.1016/j.ajog.2006.05.023 Medline

93. T. L. Barke, K. M. Money, L. Du, A. Serezani, M. Gannon, K. Mirnics, D. M. Aronoff, Sex modifies placental gene expression in response to metabolic and inflammatory stress. Placenta 78, 1-9 (2019). doi:10.1016/j.placenta.2019.02.008 Medline

94. E. P. Scully, J. Haverfield, R. L. Ursin, C. Tannenbaum, S. L. Klein, Considering how biological sex impacts immune responses and COVID19 outcomes. Nat. Rev. Immunol. 20, 442-447 (2020). doi:10.1038/s41577020-0348-8 Medline

95. L. L. Shook, E. A. Bordt, M.-C. Meinsohn, D. Pepin, R. M. De Guzman, S. Brigida, L. J. Yockey, K. E. James, M. W. Sullivan, L. M. Bebell, D. J. Roberts, A. J. Kaimal, J. Z. Li, D. Schust, K. J. Gray, A. G. Edlow, Placental expression of ACE2 and TMPRSS2 in maternal SARS-CoV-2 infection: Are placental defenses mediated by fetal sex? J. Infect. Dis. jiab335 (2021). doi:10.1093/infdis/jiab335 Medline

96. D. J. Dowling, O. Levy, Ontogeny of early life immunity. Trends Immunol. 35, 299-310 (2014). doi:10.1016/j.it.2014.04.007 Medline

97. M. J. Bunders, M. Altfeld, Implications of Sex Differences in Immunity for SARS-CoV-2 Pathogenesis and Design of Therapeutic Interventions. Immunity 53, 487-495 (2020). doi:10.1016/j.immuni.2020.08.003 Medline

98. C. L. Coe, H. R. Crispen, Social stress in pregnant squirrel monkeys (Saimiri boliviensis peruviensis) differentially affects placental transfer of maternal antibody to male and female infants. Health Psychol. 19, 554559 (2000). doi:10.1037/0278-6133.19.6.554 Medline

99. K. Maertens, T. M. P. Tran, N. Hens, P. Van Damme, E. Leuridan, Effect of Prepregnancy Pertussis Vaccination in Young Infants. J. Infect. Dis. 215, 1855-1861 (2017). doi:10.1093/infdis/jix176 Medline

100. L. Zeng, S. Xia, W. Yuan, K. Yan, F. Xiao, J. Shao, W. Zhou, Neonatal Early-Onset Infection With SARS-CoV-2 in 33 Neonates Born to Mothers With COVID-19 in Wuhan, China. JAMA Pediatr. 174, 722-725 (2020). doi:10.1001/jamapediatrics.2020.0878 Medline

101. J. Yuan, H. Qian, S. Cao, B. Dong, X. Yan, S. Luo, M. Zhou, S. Zhou, B. Ning, L. Zhao, Is there possibility of vertical transmission of COVID-19: A systematic review. Transl. Pediatr. 10, 423-434 (2021). doi:10.21037/tp20-144 Medline 
102. A. Rahman, A. Tiwari, J. Narula, T. Hickling, Importance of Feedback and Feedforward Loops to Adaptive Immune Response Modeling. CPT Pharmacometrics Syst. Pharmacol. 7, 621-628 (2018). doi:10.1002/psp4.12352 Medline

103. N. E. Webb, B. Bernshtein, G. Alter, Tissues: The unexplored frontier of antibody mediated immunity. Curr. Opin. Virol. 47, 52-67 (2021). doi:10.1016/j.coviro.2021.01.001 Medline

104. C. Zhao, Y. Gao, N. Yu, T. Li, Y. Zhang, H. Zhang, G. Lu, Y. Gao, X. Guo, Unidirectional transport of IgG by neonatal Fc receptor in human thyrocytes varies across different IgG subclasses. Mol. Cell. Endocrinol. 477, 103-111 (2018). doi:10.1016/j.mce.2018.06.006 Medline

105. K. D. Fairchild, R. G. Hudson, S. D. Douglas, S. E. McKenzie, R. A. Polin, Effect of gamma interferon on expression of Fc gamma receptors in monocytes of newborn infants and adults. Clin. Diagn. Lab. Immunol. 3 , 464-469 (1996). doi:10.1128/cdli.3.4.464-469.1996 Medline

106. R. N. Pearse, R. Feinman, K. Shuai, J. E. Darnell Jr., J. V. Ravetch, Interferon gamma-induced transcription of the high-affinity $\mathrm{Fc}$ receptor for IgG requires assembly of a complex that includes the 91-kDa subunit of transcription factor ISGF3. Proc. Natl. Acad. Sci. U.S.A. 90, 4314-4318 (1993). doi:10.1073/pnas.90.9.4314 Medline

107. Y. Li, P. Y. Lee, E. S. Kellner, M. Paulus, J. Switanek, Y. Xu, H. Zhuang, E. S. Sobel, M. S. Segal, M. Satoh, W. H. Reeves, Monocyte surface expression of Fcgamma receptor RI (CD64), a biomarker reflecting typeI interferon levels in systemic lupus erythematosus. Arthritis Res. Ther. 12, R90 (2010). doi:10.1186/ar3017 Medline

108. M. Wuhrer, M. H. J. Selman, L. A. McDonnell, T. Kümpfel, T. Derfuss, M. Khademi, T. Olsson, R. Hohlfeld, E. Meinl, M. Krumbholz, Proinflammatory pattern of IgG1 Fc glycosylation in multiple sclerosis cerebrospinal fluid. J. Neuroinflammation 12, 235 (2015). doi:10.1186/s12974-015-0450-1 Medline

109. R. Plomp, L. R. Ruhaak, H.-W. Uh, K. R. Reiding, M. Selman, J. J. Houwing-Duistermaat, P. E. Slagboom, M. Beekman, M. Wuhrer, Subclass-specific IgG glycosylation is associated with markers of inflammation and metabolic health. Sci. Rep. 7, 12325 (2017). doi:10.1038/s41598-017-12495-0 Medline

110. N. Vabret, G. J. Britton, C. Gruber, S. Hegde, J. Kim, M. Kuksin, R. Levantovsky, L. Malle, A. Moreira, M. D. Park, L. Pia, E. Risson, M. Saffern, B. Salomé, M. Esai Selvan, M. P. Spindler, J. Tan, V. van der Heide, J. K. Gregory, K. Alexandropoulos, N. Bhardwaj, B. D. Brown, B. Greenbaum, Z. H. Gümüs, D. Homann, A. Horowitz, A. O. Kamphorst, M. A. Curotto de Lafaille, S. Mehandru, M. Merad, R. M. Samstein; Sinai Immunology Review Project, Immunology of COVID-19: Current State of the Science. Immunity 52, 910-941 (2020). doi:10.1016/j.immuni.2020.05.002 Medline

111. A. E. Ades, A. Soriano-Arandes, A. Alarcon, F. Bonfante, C. Thorne, C. S. Peckham, C. Giaquinto, Vertical transmission of Zika virus and its outcomes: A Bayesian synthesis of prospective studies. Lancet Infect. Dis. 21, 537-545 (2021). doi:10.1016/S1473-3099(20)30432-1 Medline

112. M. Zdravkovic, H. J. Knudsen, X. Liu, H. Hager, V. Zachar, G. AboagyeMathiesen, P. Ebbesen, High interferon alpha levels in placenta, maternal, and cord blood suggest a protective effect against intrauterine herpes simplex virus infection. J. Med. Virol. 51, 210-213 (1997). doi:10.1002/(SICI)1096-9071(199703)51:3<210:AID-JMV11>3.0.CO;2-O Medline

113. B. W. Jagger, J. J. Miner, B. Cao, N. Arora, A. M. Smith, A. Kovacs, I. U. Mysorekar, C. B. Coyne, M. S. Diamond, Gestational Stage and IFN- $\lambda$ Signaling Regulate ZIKV Infection In Utero. Cell Host Microbe 22, 366376.e3 (2017). doi:10.1016/j.chom.2017.08.012 Medline

114. K. J. Baines, A. M. Rampersaud, D. M. Hillier, M. J. Jeyarajah, G. K. Grafham, G. Eastabrook, J. C. Lacefield, S. J. Renaud, Antiviral Inflammation during Early Pregnancy Reduces Placental and Fetal Growth Trajectories. J. Immunol. 204, 694-706 (2020). doi:10.4049/jimmunol.1900888 Medline

115. A. Senegas, O. Villard, A. Neuville, L. Marcellin, A. W. Pfaff, T. Steinmetz, M. Mousli, J. P. Klein, E. Candolfi, Toxoplasma gondii-induced foetal resorption in mice involves interferon-gamma-induced apoptosis and spiral artery dilation at the maternofoetal interface. Int. J. Parasitol. 39, 481-487 (2009). doi:10.1016/j.ijpara.2008.08.009 Medline

116. M. Niikura, S.-I. Inoue, S. Mineo, H. Asahi, F. Kobayashi, IFNGR1 signaling is associated with adverse pregnancy outcomes during infection with malaria parasites. PLOS ONE 12, e0185392 (2017). doi:10.1371/journal.pone.0185392 Medline

117. S. P. Sajuthi, P. DeFord, Y. Li, N. D. Jackson, M. T. Montgomery, J. L. Everman, C. L. Rios, E. Pruesse, J. D. Nolin, E. G. Plender, M. E. Wechsler, A. C. Y. Mak, C. Eng, S. Salazar, V. Medina, E. M. Wohlford, S. Huntsman, D. A. Nickerson, S. Germer, M. C. Zody, G. Abecasis, H. M. Kang, K. M. Rice, R. Kumar, S. Oh, J. Rodriguez-Santana, E. G. Burchard, M. A. Seibold, Type 2 and interferon inflammation regulate SARS-CoV-2 entry factor expression in the airway epithelium. Nat. Commun. 11, 5139 (2020). doi:10.1038/s41467-020-18781-2 Medline

118. A. Ghidini, C. M. Salafia, Gender differences of placental dysfunction in severe prematurity. BJOG 112, 140-144 (2005). doi:10.1111/j.14710528.2004.00308.x Medline

119. J. A. DiPietro, K. M. Voegtline, The gestational foundation of sex differences in development and vulnerability. Neuroscience 342, 4-20 (2017). doi:10.1016/j.neuroscience.2015.07.068 Medline

120. E. Bischof, J. Wolfe, S. L. Klein, Clinical trials for COVID-19 should include sex as a variable. J. Clin. Invest. 130, 3350-3352 (2020). doi:10.1172/JCI139306 Medline

121. COVID-19 Response Reporting, (available at https://www.mass.gov/infodetails/covid-19-response-reporting).

122. L. L. Shook, J. E. Shui, A. A. Boatin, S. Devane, N. Croul, L. M. Yonker, J. D. Matute, R. S. Lima, M. Schwinn, D. Cvrk, L. Gardner, R. Azevedo, S. Stanton, E. A. Bordt, L. J. Yockey, A. Fasano, J. Z. Li, X. G. Yu, A. J. Kaimal, P. H. Lerou, A. G. Edlow, Rapid establishment of a COVID-19 perinatal biorepository: Early lessons from the first 100 women enrolled. BMCMed. Res. Methodol. 20, 215 (2020). doi:10.1186/s12874-020-01102-y Medline

Acknowledgments: Funding: This work was supported by the National Institutes of Health, including NICHD (R01HD100022 to AGE and 3R01HD100022-02S2 to AGE, K12HD103096-01 to LLS, and 1R01HD094937 to DJS), NIAID (1R21AI145071 to DJS, 3R37AI08028911S1 to GA, R01AI146785 to GA, U19AI42790-01 to GA, U19AI135995-02 to GA, U19AI42790-01 to GA, and 1U01CA260476 - 01 to GA), NIMH (F32MH116604 to EAB), and NHLBI (5K08HL143183 to LMY, K08HL146963-02 to KJG and 3K08HL146963-02S1 to KJG). This work was supported in part by March of Dimes Grant No. 6-FY20-223 (to AGE). This material is based upon work supported by the National Science Foundation Graduate Research Fellowship under Grant No (\#1745302) to KMP. Additional support was provided by the Massachusetts General Hospital Department of Surgery, the Robert and Donna E. Landreth Family Fund, the Department of Pediatrics at Massachusetts General Hospital, The Regione Campania Italy (CUP G58D20000240002 - SURF 20004BP000000011, to AF), the Gates Foundation, the Ragon Institute of MGH and MIT, and the Massachusetts General Hospital and Brigham and Women's Hospital Departments of Obstetrics and Gynecology. Author Contributions: E.A.B., L.L.S., G.A., and A.G.E. conceptualized and designed the study. E.A.B., L.L.S., C.A., K.M.P., R.M.D.G., M-C.M., M.C., S.F., L.J.Y., S.B., K.G., G.A., and A.G.E. performed the experiments (placental gene and protein expression and placental quantitative immunohistochemistry performed by E.A.B., L.L.S., R.M.D.G., S.B., L.J.Y., M-C.M., M.C., D.J.R., A.G.E.; systems serology and antibody glycosylation experiments performed by C.A., S.F., and overseen by G.A; original sample collection and processing for the serology experiments was performed by R.M.D.G., S.B., L.L.S., E.A.B., L.J.Y., K.G., A.G.E.) Data analysis was performed by E.A.B., C.A., K.M.P., M-C.M., K.J., D.J.R., D.L., G.A., A.G.E. The original draft was written by E.A.B., L.L.S., C.A., G.A., and A.G.E. The manuscript was reviewed and edited by E.A.B., L.L.S., C.A., K.M.P., R.M.D.G., M-C.M., M.C., S.F., L.J.Y., K.J., R.L., L.M.Y., A.F., S.B., L.M.B., D.J.R., D.P., J.R.H., S.D.B., J.Z.L., A.K., D.J.S., K.J.G., D.L., G.A., and 
A.G.E. Competing interests: K.J.G. has consulted for Illumina, BillionToOne, and Aetion outside the submitted work. A.F. reported serving as a cofounder and owning stock in Alba Therapeutics and serving on scientific advisory boards for NextCure and Viome outside the submitted work. G.A. reported serving as a founder of Systems Seromyx. J.Z.L. reported serving as a consultant for Abbvie and Jan Biotech. D.P. reported owning stock in Gilead Sciences, BioNano

Genomics, Biogen, Bluebird Bio, ImmunoGen, Pfizer, and Bristol-Myers Squibb. D.J.R. reported receiving author royalties from UpToDate and Cambridge University Press outside the submitted work. Any opinion, findings, and conclusions or recommendation expressed in this material are those of the authors and do not necessarily reflect the views of the National Science Foundation. All others report no conflicts of interest. Data and materials availability: All data associated with this study are present in the paper or the Supplementary Materials. This work is licensed under a Creative Commons Attribution 4.0 International (CC BY 4.0) license, which permits unrestricted use, distribution, and reproduction in any medium, provided the original work is properly cited. To view a copy of this license, visit

https://creativecommons.org/licenses/by/4.0/. This license does not apply to figures/photos/artwork or other content included in the article that is credited to a third party; obtain authorization from the rights holder before using this material.

Submitted 28 March 2021

Accepted 3 September 2021

Published First Release 19 October 2021

10.1126/scitranslmed.abi7428 


\section{OSARS-CoV-2 Negative}
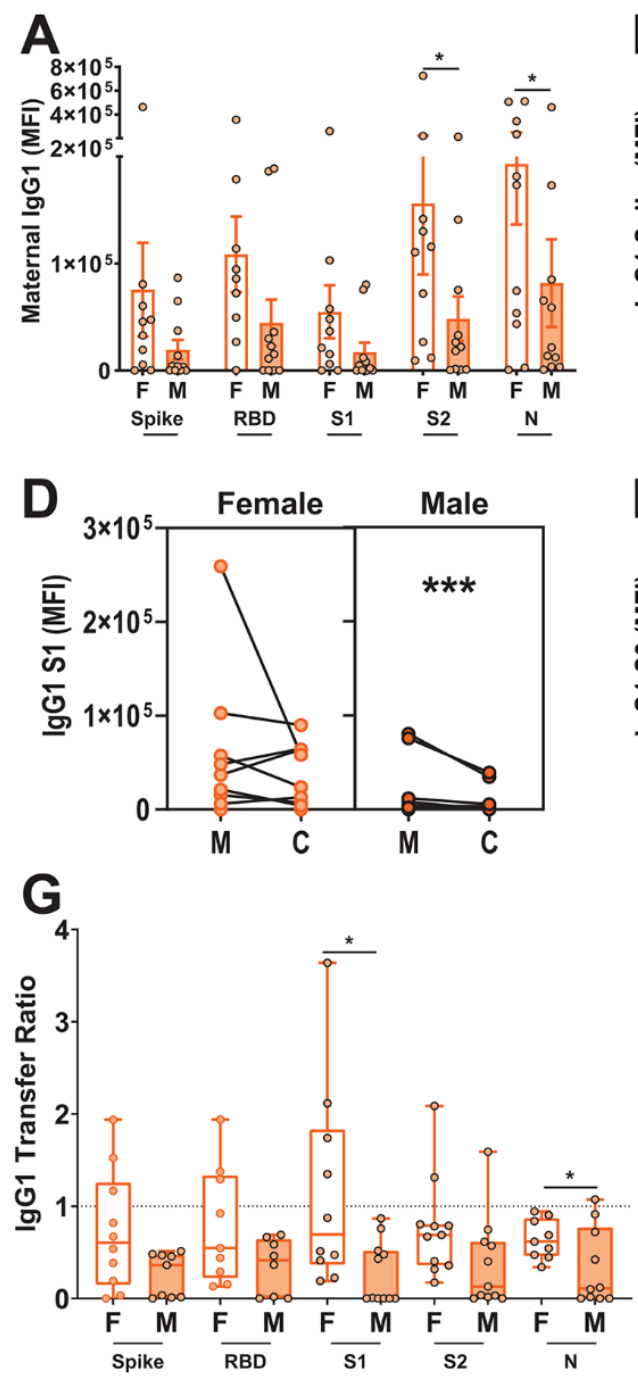

I

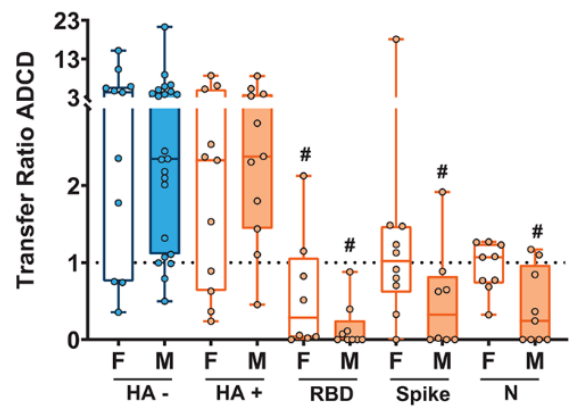

B
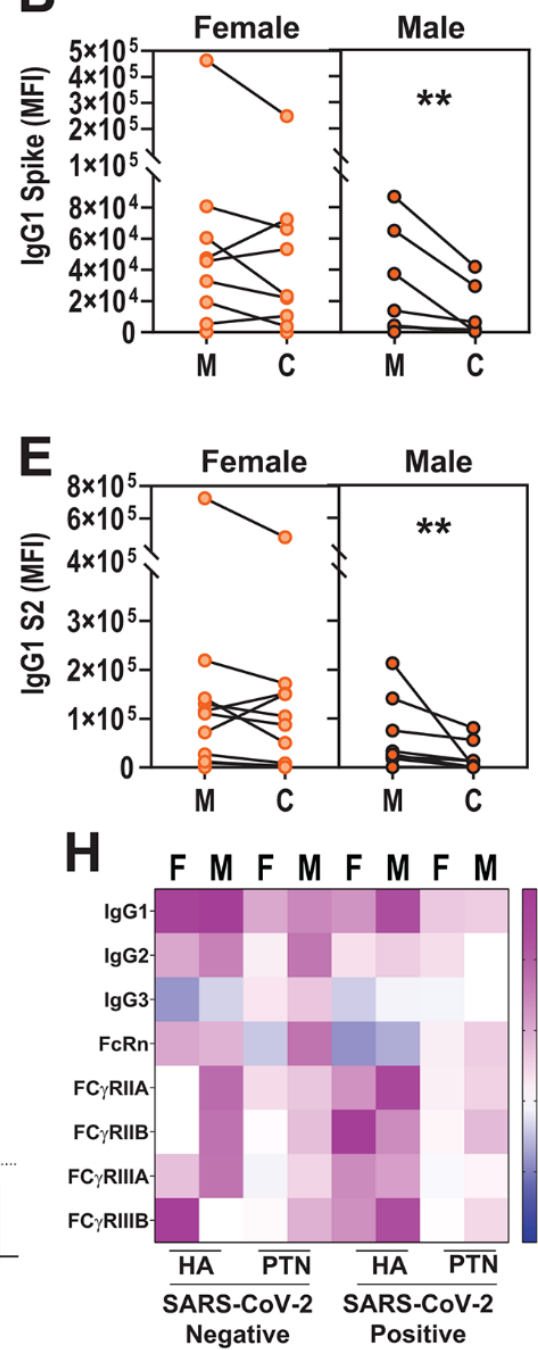

J

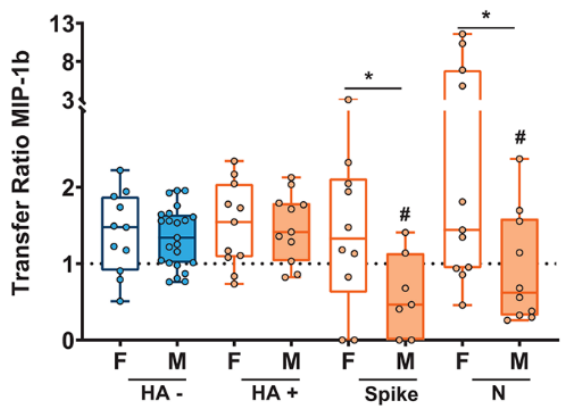

C
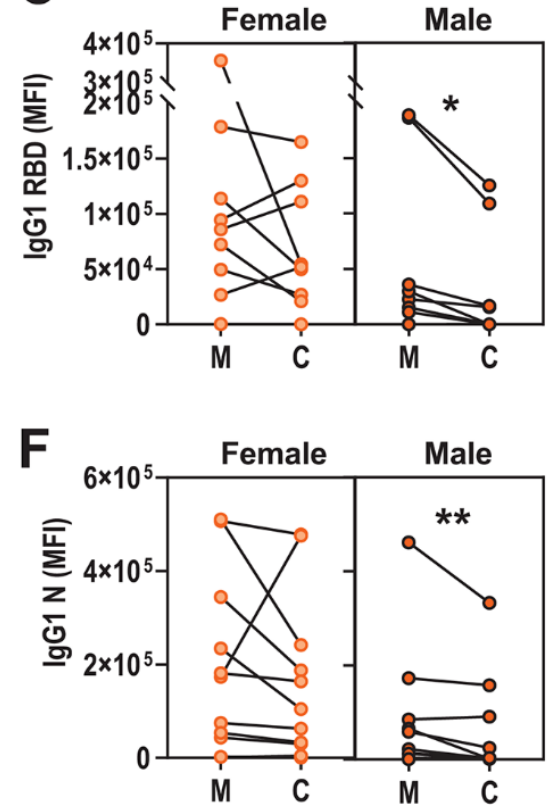

F $M F M F$

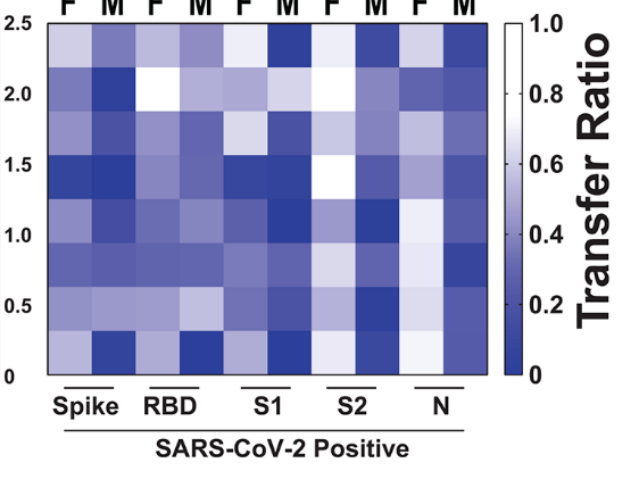

K

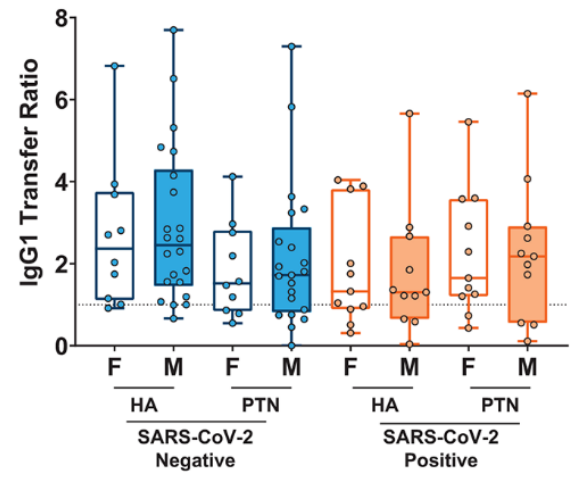


Fig. 1. SARS-CoV-2 positive mothers with male fetuses demonstrate reduced maternal titers and placental transfer of SARS-CoV-2-specific antibodies compared to those with female fetuses. A. Bar graphs depict spike protein-, RBD-, S1-, S2-, and N protein-specific maternal IgG1 titers ( $n=11$ per group). F indicates female and $\mathrm{M}$ indicates male fetus. Differences across groups were assessed by two-way ANOVA followed by Bonferroni post-hoc analyses. There was a main effect of fetal sex on maternal lgG1 titers. MFI, Median Fluorescence Intensity. ${ }^{*} p<0.05$. B to F. Dot plots showing relative spike protein- (B), RBD- (C), S1(D), S2- (E), and N protein-specific (F) maternal blood (M) and cord blood (C) titers of IgG1 ( $n=11$ per group). Female neonates of -CoV-2 positive mothers are shown in light orange. Males born to SARS-CoV-2 positive mothers are shown in dark orange. All values reflect PBS background correction. Group differences were assessed by Wilcoxon matched-pairs signed rank test. ${ }^{*} p<0.05$, ${ }^{*} p<0.01,{ }^{* * *} p<0.001$. G. Box-andwhisker plots show the placental transfer ratios (cord:maternal ratios) for IgG1 against the SARS-CoV-2 antigens spike protein, RBD, S1, S2, and N. SARS-CoV-2 positive maternal status is shown in orange (female, $\mathrm{F}$ : open bars; male, M: shaded bars). All values are PBS background corrected. ( $n=11$ per group). Differences across groups were assessed by Kruskal-Wallis test followed by Dunn's post-hoc analyses. Dotted line denotes a transfer ratio of 1 or $100 \%$. ${ }^{*} \mathrm{p}<0.05$. H. Heatmap depicting the median PBS backgroundcorrected cord:maternal transfer ratio of HA, PTN, spike protein, RBD, S1, S2, and N protein across all antibody subclasses and Fc receptor binding profiles in both SARS-CoV-2 negative and positive maternal:neonate dyads. I and J. Box-and-whisker plots depicting transfer ratios (cord:maternal) for HA, RBD, spike protein, or $N$ protein-specific antibodies ( $n=11$ to 23 per group) mediating antibody-dependent complement deposition (ADCD, I) and macrophage inflammatory protein-1 $\beta$ (MIP-1 $\beta$ ) expression (J). SARSCoV-2 negative maternal status is shown in blue (female: open bars; male: shaded bars) and SARS-CoV-2 positive maternal status is shown in orange (female: open bars; male: shaded bars). HA - indicates presence of antibodies specific to HA antigen in SARS-CoV-2 negative pregnancies, HA + indicates presence of antibodies specific to HA antigen in SARS-CoV-2 positive pregnancies. Differences across groups were assessed by Kruskal-Wallis test followed by Dunn's post-hoc analyses. For each SARS-CoV-2 antigen, posthoc analyses were performed against the HA-specific activity using the matched SARS-CoV-2 positive dyad. $\# p<0.01$ compared to HA transfer ratio for SARS-CoV-2 positive samples of that sex, ${ }^{*} p<0.01$ compared to indicated group. K. The box-and-whisker plots show the transfer ratios (cord:maternal ratio) for lgG1 against HA and PTN in maternal:neonate dyads from either SARS-CoV-2 negative or SARS-CoV-2 positive pregnancies ( $n=11$ to 23 per group). SARS-CoV-2 negative are shown in blue (female: open bars; male: shaded bars) and SARS-CoV-2 positive are shown in orange (female: open bars; male: shaded bars). Differences across groups were assessed by Kruskal-Wallis test followed by Dunn's post-hoc analyses. In panels I to $\mathrm{K}$, dotted line denotes transfer ratio of 1 or $100 \% .{ }^{*} \mathrm{p}<0.05$. For box and whisker plots in $\mathrm{A}, \mathrm{G}, \mathrm{I}, \mathrm{J}$, and $\mathrm{K}$, the box extends from $25^{\text {th }}$ to $75^{\text {th }}$ percentile, the whiskers depict minimum and maximum, and horizontal line depicts the median. 


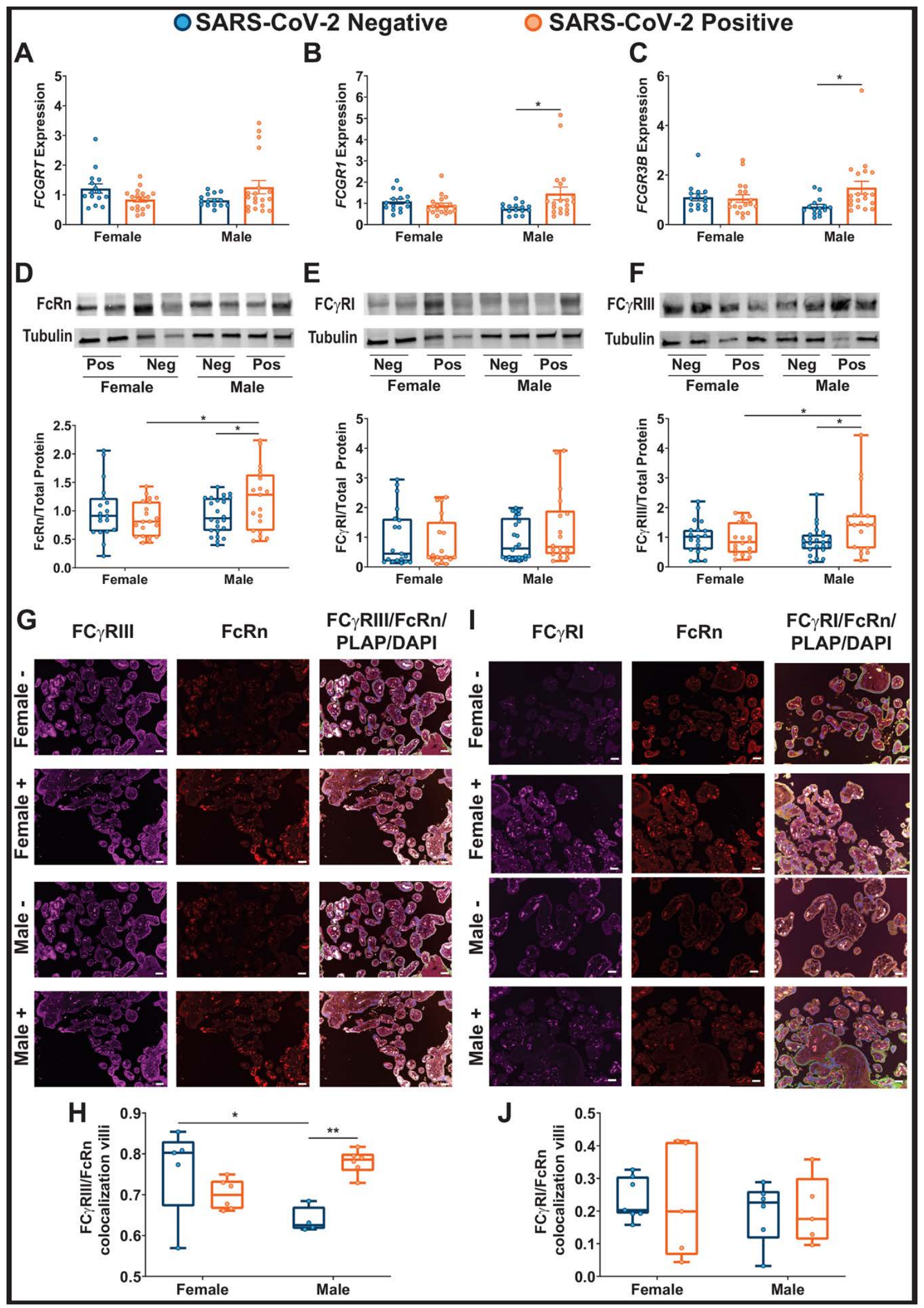


Fig. 2. Sexually dimorphic regulation of placental $\mathrm{Fc}$ receptor gene and protein expression is observed in the setting of maternal SARS-CoV-2 infection. (A to C) RT-qPCR analyses of male or female placental expression of FCGRT (A), FCGR1 (B), and FCGR3B (C) in placental biopsies from SARS-CoV-2 negative (blue) or SARS-CoV-2 positive (orange) pregnancies ( $n=15$ to 18 per group). Expression shown are relative to reference genes YWHAZ and TOP1. Bar plots in A to $C$ indicate mean \pm standard error of the mean (SEM). (D to F) Representative immunoblots and quantification of fetal female or fetal male expression of $F c R n(D)$, $F_{\gamma} R 1(E)$, and $F C_{\curlyvee} R 3(F)$ in placental biopsies from SARS-CoV-2 negative (blue) or SARS-CoV-2 positive (orange) pregnancies ( $n=19$ per group). Neg and Pos on Western blot designates SARS-CoV-2 negative and positive pregnancies. For box and whisker plots $D$ to $F$, the box extends from $25^{\text {th }}$ to $75^{\text {th }}$ percentile, the whiskers depict minimum and maximum, and horizontal line depicts the median. (G) Placental tissue sections from SARS-CoV-2 positive and SARS-CoV-2 negative mothers were stained for FC $\curlyvee R 3$ (purple), FcRn (red), and placental alkaline phosphatase (PLAP, green), a trophoblast marker, and 4',6-diamidino-2-phenylindole (DAPI, blue). (H) Box-and-whisker plots showing FC $\gamma R I I I / F c R n$ co-localization in placental villi ( $n=4$ to 6 per group). (I) Placental tissue sections from SARS-CoV-2 positive and SARS-CoV-2 negative mothers were stained for FCҮR1 (purple), FcRn (red), and placental alkaline phosphatase (PLAP, green), a trophoblast marker, and DAPI (blue). (J) Box-and-whisker plots showing $\mathrm{FC}_{\gamma} \mathrm{R} 1 / \mathrm{FcRn}$ co-localization in placental villi ( $\mathrm{n}$ $=5$ to 7 per group). Scale bars in $(G)$ and $(\mathrm{I})$ indicate $100 \mu \mathrm{m}$. For box and whisker plots in $\mathrm{H}$ and $\mathrm{J}$, the box extends from $25^{\text {th }}$ to $75^{\text {th }}$ percentile, the whiskers depict minimum and maximum, and horizontal line depicts the median. Differences across groups were assessed by two-way ANOVA followed by Bonferroni's post-hoc analyses. ${ }^{*} p<0.05,{ }^{* *} p<0.01$. 
O SARS-CoV-2 Positive Bulk Glycans

A

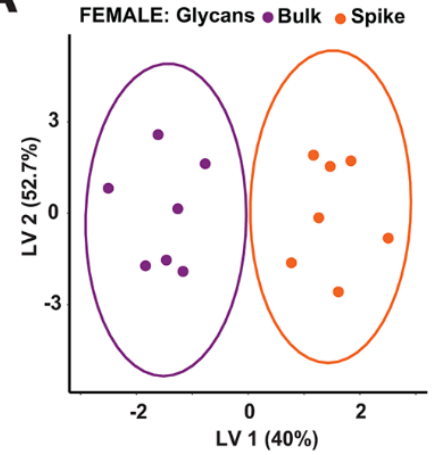

\section{SARS-CoV-2 Positive Spike Glycans}

B

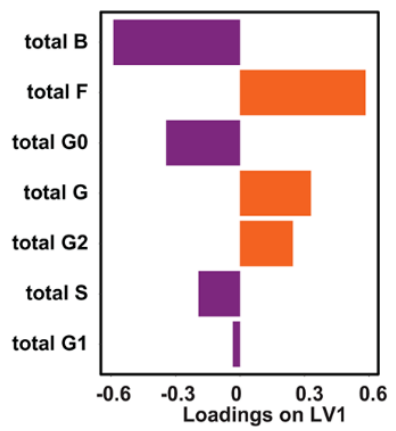

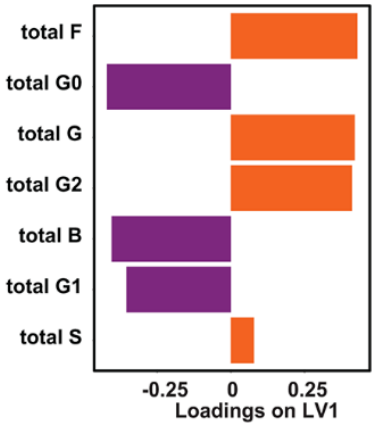
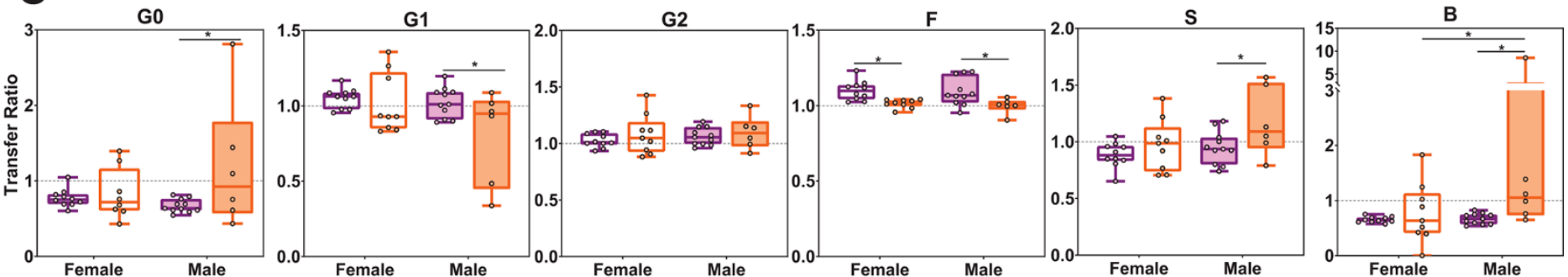

Fig. 3. Sex differences in placental transfer are driven by differences in bulk versus Spike protein-specific Fc-glycan transfer. (A and B) A multi-level orthogonal partial least squares discriminant analysis (O-PLSDA) was built using bulk (purple) and spike protein-specific (orange) antibody glycan data from SARS-CoV-2positive mothers pregnant with a female fetus (A) or male fetus (B) for which matched data were available. Each maternal sample is depicted as a dot on the scores plot (left). The glycan feature loadings on the first latent variable (LV1) are depicted by the bar graph (right). The model performance was assessed using leaveone-out cross validation, with the average accuracy scores reported to be $98 \%$ and $100 \%$ predictive accuracy for the female and male m-O-PLSDA models, respectively. (C) Box-and-whisker plots showing the transfer ratios (cord:maternal ratios) for bulk and spike protein-specific Fc-glycans. Glycoforms depicted are agalactosylated (G0), monogalactosylated (G1), digalactyosylated (G2), fucosylated (F), sialylated (S), and bisected n-acetyl-glucosamine (GlcNAc, B). Bulk glycans are shown in purple, spike protein-specific glycans are shown in orange ( $n=8$ to 11 per group). Pregnancies with female neonates are shown as open bars, whereas pregnancies with male neonates are shown as shaded bars. For box and whisker plots in (C), box extends from $25^{\text {th }}$ to $75^{\text {th }}$ percentile, the whiskers depict minimum and maximum, and horizontal line depicts the median. Differences across groups were assessed by two-way ANOVA followed by FDR multiple comparisons correction post-hoc analyses. ${ }^{*} \mathrm{p}<0.05$. 


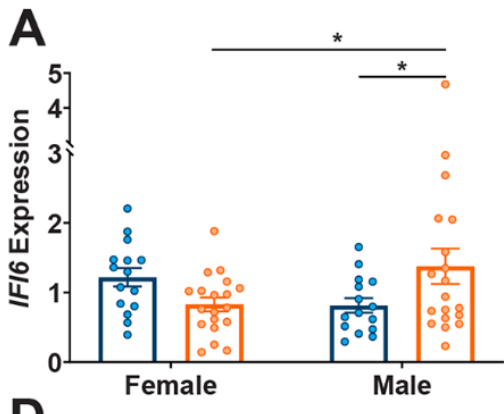

\section{B \\ E}
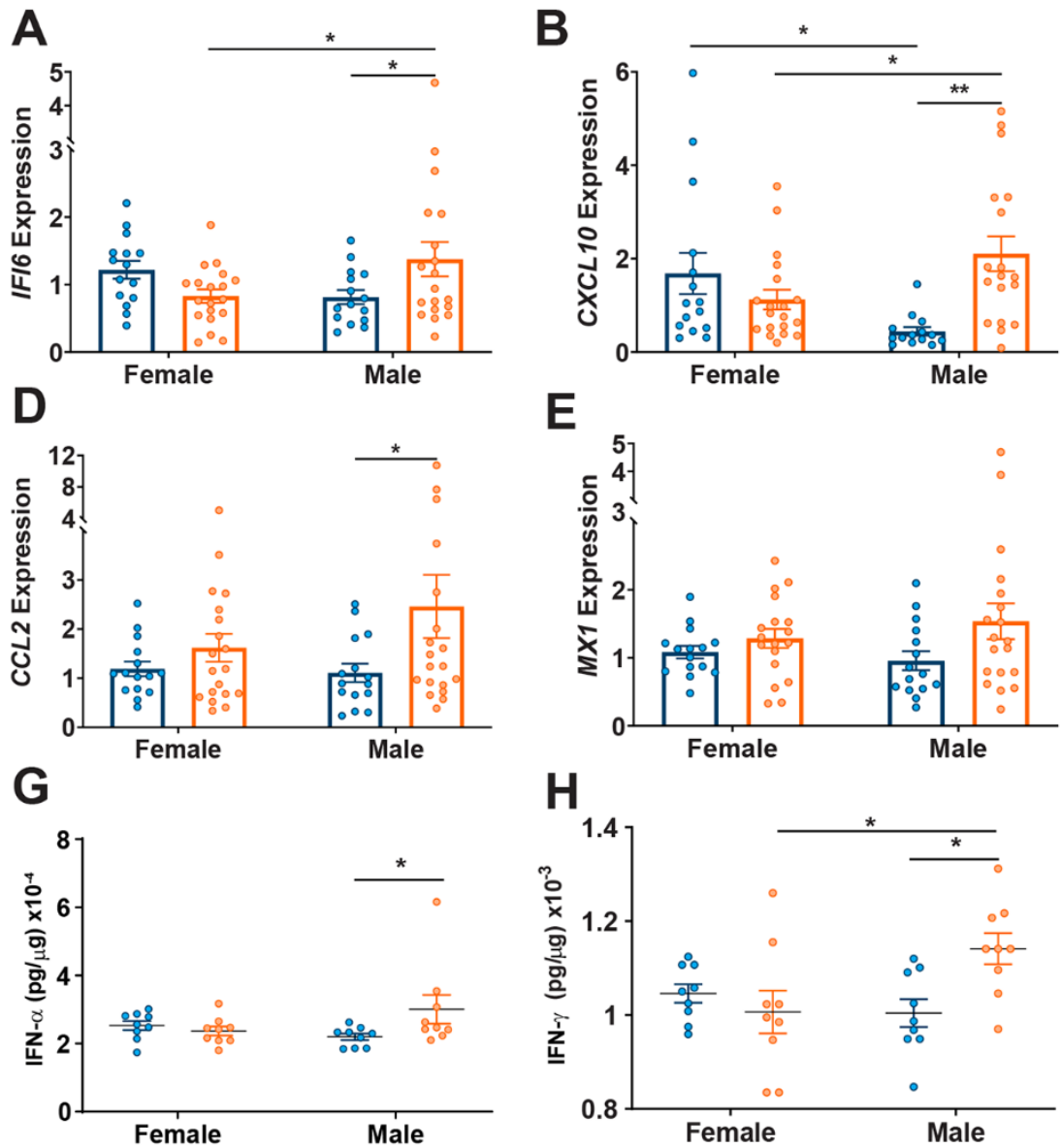

J

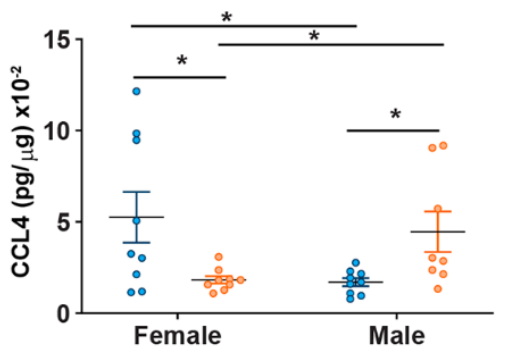

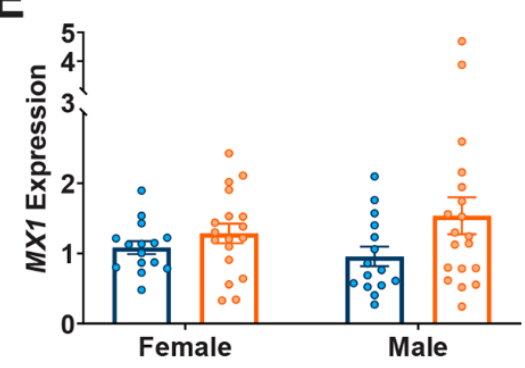
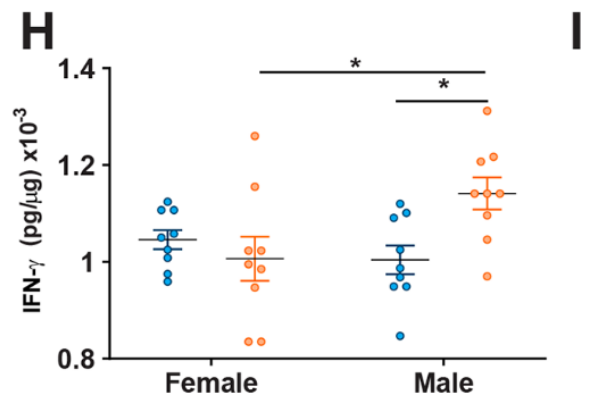

K SARS-CoV-2 - SARS-CoV-2 +

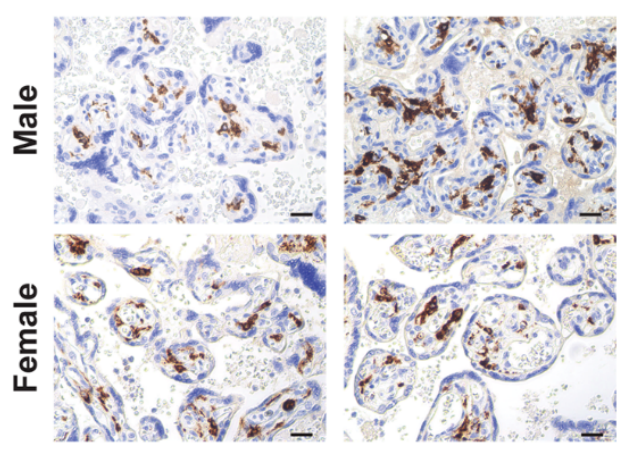

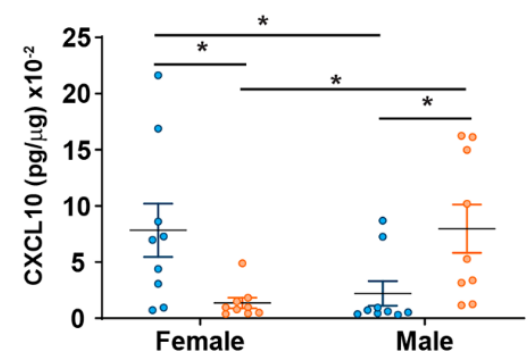

C

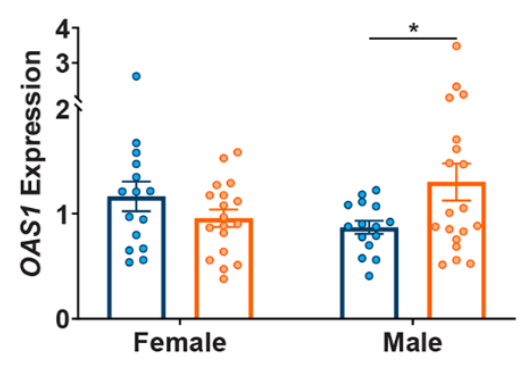

$\mathbf{F}$
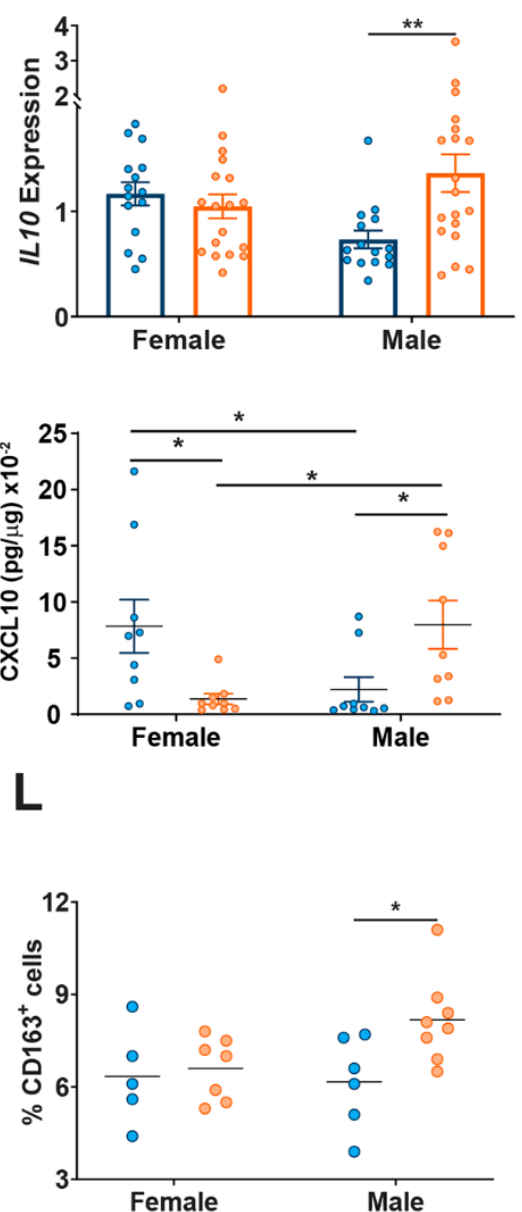

Fig. 4. Male-specific up-regulation of interferon stimulated genes in placentas exposed to maternal SARS-CoV2 infection. (A to F) RT-qPCR analyses of male or female placental expression of IFI6 (A), CXCL10 (B), OAS1 (C), CCL2 (D), MX1 (E), and ILIO (F) in placental biopsies from SARS-CoV-2 negative (blue) or SARS-CoV-2 positive (orange) pregnancies ( $n=15$ to 18 per group). Expression shown are relative to reference genes YWHAZ and TOP1. Bar plots in (A to F) indicate mean \pm SEM. (G to J) Placental homogenate protein concentrations of IFN- $\alpha(G)$, IFN- $\gamma$ $(\mathrm{H})$, CXCL10 (I), and CCL4 $(\mathrm{J})$ were quantified by Luminex multiplex assay ( $\mathrm{n}=9$ per group). Data are presented as mean \pm SEM. ( $K$ and L) Representative immunohistochemistry images (K) and quantification (L) of CD163-positive cells (brown) in placental sections from SARS-CoV-2 negative (blue) or SARS-CoV-2 positive (orange) pregnancies are shown ( $n=5$ to 8 per group). Scale bars in $(K)$ indicate $100 \mu \mathrm{m}$. Horizontal bars in $(L)$ indicate mean. Differences across groups were assessed by two-way ANOVA followed by Bonferroni's post-hoc analyses. ${ }^{*} p<0.05,{ }^{* *} p<0.01$ 


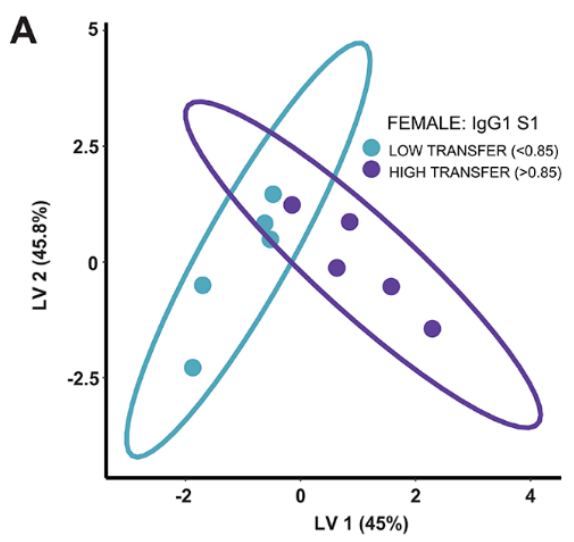

C

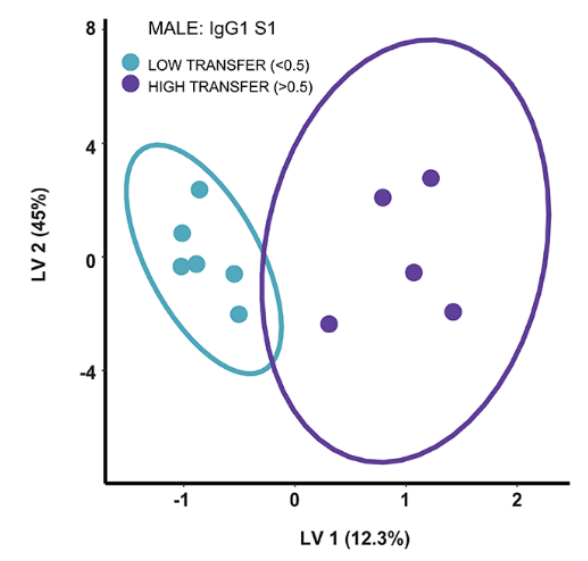

B

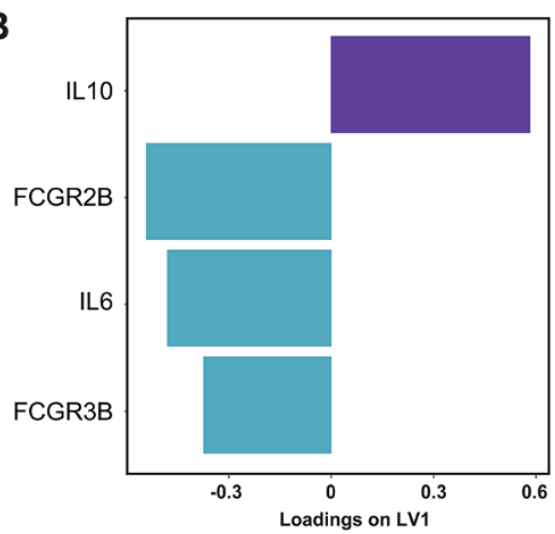

D

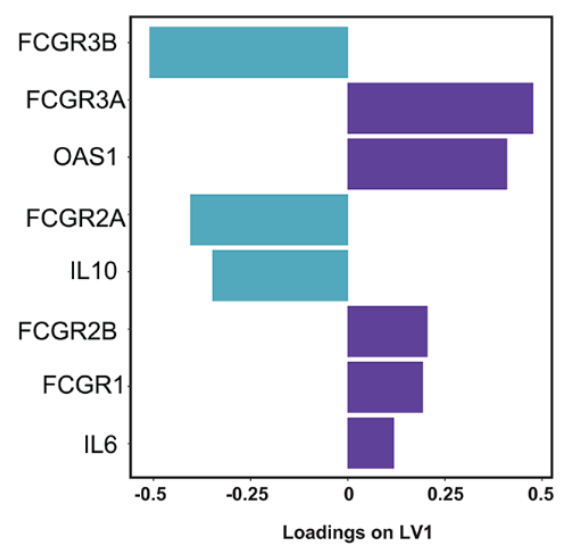

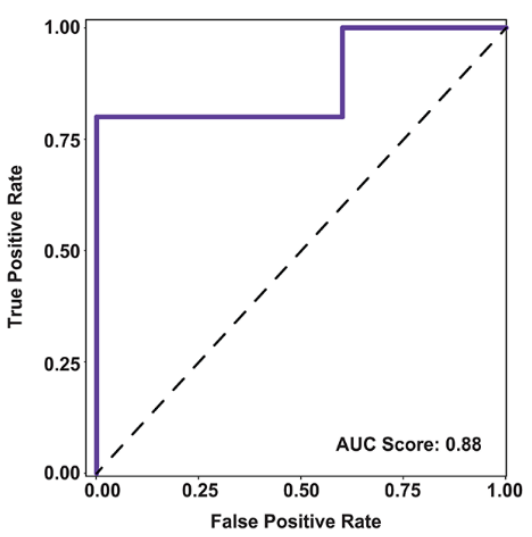

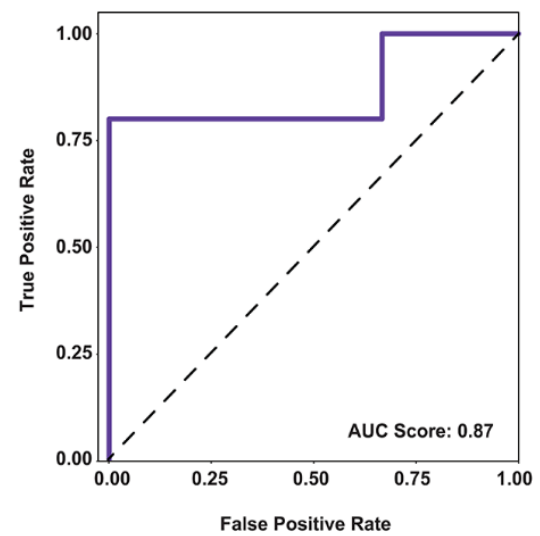

Fig. 5. Placental gene expression impacts transplacental antibody transfer. (A) O-PLSDA model classifying relatively low (ratio $<0.85$ ) versus high (ratio $>0.85$ ) IgG1 S1 transfer to female neonates based on placental gene expression. The model was built on gene expression features after LASSO feature selection. Each dot represents one mother-cord pair. (B) Gene expression feature loadings on the first latent variable (LV1) for the female model in (A). Bar color corresponds with which transfer classification (low versus high) is characterized by enriched expression of that gene, with blue bars enriched in low transfer and purple bars enriched in high transfer. The receiver operating characteristic (ROC) curve (solid purple line) for this model quantifies the accuracy in classifying lgG1 S1 transfer to female neonates after leave-one-out cross validation. The area under the curve (AUC) score is reported. The black dashed line represents the expected performance of a random model (AUC Score $=0.5$ ). (C) O-PLSDA model classifying relatively low (ratio < 0.5) versus high (ratio > 0.5) lgG1 S1 transfer to male neonates based on placental gene expression. The model was built on gene expression features after LASSO feature selection. (D) Gene expression feature loadings on the first latent variable (LV1) for the male model in (C). Bar color corresponds with which transfer classification (low versus high) is characterized by enriched expression of that gene, with blue bars enriched in low transfer and purple bars enriched in high transfer, respectively. The ROC curve (solid purple line) for this model quantifies the accuracy in classifying IgG1 S1 transfer to male neonates after leave-one-out cross validation. The AUC score is reported with black dashed line representing the expected performance of a random model (AUC Score $=0.5$ ). 
Table 1. Demographic and clinical characteristics of study cohort by fetal sex and maternal SARS-CoV-2 status. Abbreviations: DM/GDM, diabetes mellitus/gestational diabetes mellitus; BMI, body mass index; GA, gestational age; N/A, not applicable. ${ }^{a}$ SARS-CoV-2 status determined by nasopharyngeal RT PCR at time of sample collection. If a participant was SARS-CoV-2 positive at any time in pregnancy, she was included in "SARS-CoV-2 positive" category. ${ }^{\mathrm{b}}$ Significant differences between groups were determined using chi-square test for categorical variables, and Kruskal-Wallis test for continuous variables presented as median [interquartile range]. ${ }^{\mathrm{c}}$ Disease severity classifications are based on published NIH criteria.

\begin{tabular}{|c|c|c|c|c|c|c|}
\hline & \multirow[t]{2}{*}{ All (68) } & \multicolumn{2}{|c|}{ Female } & \multicolumn{2}{|c|}{ Male } & \multirow[t]{2}{*}{ P-value $^{b}$} \\
\hline & & $\begin{array}{c}\text { SARS-CoV-2 } \\
\text { negative } \\
(15) \\
\end{array}$ & $\begin{array}{c}\text { SARS-CoV-2 } \\
\text { positive } \\
(\mathbf{1 9})^{\mathrm{a}} \\
\end{array}$ & $\begin{array}{c}\text { SARS-CoV-2 } \\
\text { negative } \\
(15) \\
\end{array}$ & $\begin{array}{c}\text { SARS-CoV-2 } \\
\text { positive } \\
(19)^{\mathrm{a}} \\
\end{array}$ & \\
\hline Maternal Age, years & $\begin{array}{c}33 \\
{[28-38]}\end{array}$ & $\begin{array}{c}33 \\
{[30-36]}\end{array}$ & $\begin{array}{c}34 \\
{[30-40]}\end{array}$ & $\begin{array}{c}30 \\
{[27-37]}\end{array}$ & $\begin{array}{c}31 \\
{[26-36]}\end{array}$ & 0.34 \\
\hline Parity, $n$ & $\begin{array}{c}1 \\
{[0-2]}\end{array}$ & $\begin{array}{c}1 \\
{[0-2]}\end{array}$ & $\begin{array}{c}1 \\
{[0-2]}\end{array}$ & $\begin{array}{c}1 \\
{[0-2]}\end{array}$ & $\begin{array}{c}1 \\
{[0-2]}\end{array}$ & 0.34 \\
\hline Race, $n(\%)$ & & & & & & 0.19 \\
\hline White & $40(59)$ & $11(73)$ & $8(42)$ & $12(80)$ & $9(59)$ & \\
\hline Black & $5(7)$ & $1(7)$ & $3(16)$ & $0(0)$ & $1(7)$ & \\
\hline Asian & $1(1)$ & $0(0)$ & $0(0)$ & $1(7)$ & $0(0)$ & \\
\hline Other & $12(18)$ & $3(20)$ & $4(21)$ & $1(7)$ & $4(8)$ & \\
\hline Not Reported & $10(15)$ & $0(0)$ & $4(21)$ & $1(7)$ & $5(15)$ & \\
\hline Ethnicity, $n$ (\%) & & & & & & 0.01 \\
\hline Hispanic & $32(47)$ & $4(27)$ & $11(58)$ & $2(13)$ & $15(79)$ & \\
\hline Non-Hispanic & $33(48)$ & $10(67)$ & $7(37)$ & $12(80)$ & $4(21)$ & \\
\hline Not Reported & $3(4)$ & $1(7)$ & $1(5)$ & $1(7)$ & $0(0)$ & \\
\hline $\begin{array}{l}\text { Chronic hypertension, } \\
n(\%)\end{array}$ & $0(0)$ & $0(0)$ & $0(0)$ & $0(0)$ & $0(0)$ & N/A \\
\hline $\mathrm{DM} / \mathrm{GDM}, n(\%)$ & $6(9)$ & $1(7)$ & $3(16)$ & $1(7)$ & $1(5)$ & 0.67 \\
\hline $\mathrm{BMI} \geq 30 \mathrm{~kg} / \mathrm{m}^{2}, n(\%)$ & $20(29)$ & $2(13)$ & $7(37)$ & $3(20)$ & $8(42)$ & 0.21 \\
\hline $\begin{array}{l}\text { Pre-pregnancy BMI, } \\
\mathrm{kg} / \mathrm{m}^{2}\end{array}$ & $\begin{array}{c}27.4 \\
{[21.5-30.8]}\end{array}$ & $\begin{array}{c}25.8 \\
{[21.6-29.4]}\end{array}$ & $\begin{array}{c}28.5 \\
{[26.5-32.7]}\end{array}$ & $\begin{array}{c}21.5 \\
{[20.3-29.8]}\end{array}$ & $\begin{array}{c}29.5 \\
{[22.3-32.0]}\end{array}$ & 0.06 \\
\hline GA at delivery, weeks & $\begin{array}{c}39.2 \\
{[38.6-40.3]}\end{array}$ & $\begin{array}{c}39.3 \\
{[39.0-39.4]}\end{array}$ & $\begin{array}{c}39.3 \\
{[38.4-40.1]}\end{array}$ & $\begin{array}{c}39.1 \\
{[39.0-41.1]}\end{array}$ & $\begin{array}{c}39.0 \\
{[35.3-40.3]}\end{array}$ & 0.09 \\
\hline Any labor, $n(\%)$ & $52(76)$ & $8(53)$ & $16(84)$ & $11(73)$ & $17(89)$ & 0.07 \\
\hline $\begin{array}{l}\text { Neonatal birthweight, } \\
g\end{array}$ & $\begin{array}{c}3283 \\
{[3005-3590]}\end{array}$ & $\begin{array}{c}3400 \\
{[3060-3590]}\end{array}$ & $\begin{array}{c}3255 \\
{[2920-3340]}\end{array}$ & $\begin{array}{c}3435 \\
{[3260-3730]}\end{array}$ & $\begin{array}{c}3115 \\
{[2615-3590]}\end{array}$ & 0.06 \\
\hline $\begin{array}{l}\text { GA at positive SARS- } \\
\text { CoV-2 test, weeks } \\
\text { COVID-19 disease }\end{array}$ & $\begin{array}{c}38.7 \\
{[35.6-39.6]}\end{array}$ & $\mathrm{N} / \mathrm{A}$ & $\begin{array}{c}36.3 \\
{[32.4-39.4]}\end{array}$ & N/A & $\begin{array}{c}36.3 \\
{[32.4-39.5]}\end{array}$ & 0.90 \\
\hline $\begin{array}{l}\text { severity at diagnosis }{ }^{\mathrm{c}} \text {, } \\
n\end{array}$ & & & & & & 0.82 \\
\hline Asymptomatic & $16(42)$ & $\mathrm{N} / \mathrm{A}$ & $8(42)$ & $\mathrm{N} / \mathrm{A}$ & $8(42)$ & \\
\hline Mild/Moderate & $19(50)$ & $\mathrm{N} / \mathrm{A}$ & $9(47)$ & $\mathrm{N} / \mathrm{A}$ & $10(53)$ & \\
\hline Severe/Critical & $3(8)$ & $\mathrm{N} / \mathrm{A}$ & $2(11)$ & $\mathrm{N} / \mathrm{A}$ & $1(5)$ & \\
\hline $\begin{array}{l}\text { Time between SARS- } \\
\text { CoV-2 symptom onset } \\
\text { and delivery, days }\end{array}$ & $36.5[18-57]$ & N/A & $44[28-64]$ & N/A & $32[8-51]$ & 0.18 \\
\hline
\end{tabular}

